\title{
Co-Transplantation of Marginal Mass Allogeneic Islets with 3D- Culture-Derived Adult Human Skin Cells Improves Glycemia in Diabetic Mice
}

Talita C. Oliveira

University of São Paulo

Maria F. Forni

University of São Paulo

Ancély F. Santos

University of São Paulo

Rosangela A. M. Wailemann

University of São Paulo

Leticia F. Terra

University of São Paulo

Luz Andreone

Instituto de Investigaciones en Medicina Traslacional, CONICET- Universidad Austral

Vinicius M. Gomes

University of São Paulo

Janaina Macedo Silva

Biosciences Institute, USP

Livia Rosa-Fernandes

Biosciences Institute, USP

Mari C. Sogayar

USP

Giuseppe Palmisano

Biosciences Institute, USP

Leticia Labriola

University of São Paulo

Marcelo J. Perone ( $\nabla$ mperone-conicet@austral.edu.ar)

Instituto de Investigaciones en Medicina Traslacional, CONICET- Universidad Austral

\section{Research Article}

Keywords: Mesenchymal stem cells, cell therapy, type 1 diabetes, three-dimensional (3D) culture, hanging drop

Posted Date: October 7th, 2021

DOI: https://doi.org/10.21203/rs.3.rs-951683/v1

License: (1) This work is licensed under a Creative Commons Attribution 4.0 International License. Read Full License 


\section{Abstract}

Background. Pancreatic islets transplantation represents a promising therapeutic option for severe type 1 diabetes (T1D). Maintenance of long-term viability of transplanted islets still requires improvement. Stem cell use represents an option to repair and replace damaged islets or, alternatively, b cells in T1D. Mesenchymal stem cells (MSC) have been proposed as adjuvants for islet transplantation, facilitating grafting and improving their functionality. Aggregation of stem cells has gained interest in providing physiological interactions between cells and enhancing the in situ concentration of modulators of inflammation and immunity.

Methods. We established a hanging-drop culture by the spontaneous aggregation of adult human skin fibroblast-like cells as spheroids. Adult skin spheroid-derived cells (SphCs) were characterized in vitro and in vivo. We assessed the potential benefit of SphCs as adjuvants to improve islet functionality by cotransplantation with a marginal mass of allogeneic islets in an experimental diabetic mouse model. We characterized the secretome of SphCs by mass spectrometry-based proteomics.

Results. SphCs were characterized as multipotent progenitors by their surface expression of markers analyzed by flow cytometry and multilineage germ differentiation capacity. Coculture of SphCs with anti-CD3-stimulated mouse splenocytes diminished the proliferation of T-CD4 ${ }^{+}$lymphocytes and biased splenocyte cytokine secretion through an increase in the Th2/Th1 ratio. SphCs conditioned media attenuated apoptosis of islets induced by inflammatory cytokine challenge in vitro. Administration (i.t.) of SphCs showed the absence of tumorigenicity in immune-deficient mice.

SphCs improved glycemic control when cotransplanted with a marginal mass of allogeneic islets in an experimental diabetic mouse model without pharmacological immunosuppression. SphCs' protein secretome differed from its paired skin fibroblast-like counterpart in containing $70 \%$ of up- and downregulated proteins and biological processes that overall positively influence islets such as cytoprotection, cellular stress, metabolism, and survival.

Conclusions. Hanging-drop cell culture methodology might contribute to the development of an efficient way to improve transplantation outcome by reducing undesirable consequences of pharmacological immunosuppression as well as the number of allogeneic islets required to achieve normoglycemia in T1D transplanted patients. Further studies might determine whether the identified proteins sustain immunomodulation and/or cytoprotective effects in transplanted allogeneic islets.

\section{Introduction}

T1D arises with progressive dysfunction and loss of insulin-producing $\beta$ cells due to an autoimmune process; its incidence has increased markedly in recent years $(1,2)$. Insulin remains as a palliative for T1D. Therapeutic interventions involving immunosuppressive drugs failed to achieve lasting remission, and beneficial effects were only observed for short periods of time during treatment (3-5).

Attention has been focused on the use of cell therapy to repair damaged tissues, including islets and $\beta$ cells, in T1D $(6,7)$. Notably, the significant advance introduced by the use of potent induction therapy in addition to the management of anti-cytokines before transplantation leads to 5 -year insulin independence rates greater than $50 \%$, as reported by the 2014 Collaborative Islet Transplant Registry (CITR) $(8,9)$.

Stem cells have shown promising experimental results, but their use has faced limited effectiveness owing to the low survival rates and susceptibility to environmental stress after transplantation (10). Multipotent stem cells, including mesenchymal stromal cells (MSCs), differentiate into cell types of a specific germ layer (11). Embryonic stem (ES) cells and induced pluripotent stem cells (iPSCs) possess the potential to give rise to cells of all three germ lineages (e.g., mesodermal, endodermal, and ectodermal) $(12,13)$. Concerns have arisen regarding the use of ES cells due to teratoma formation through uncontrolled self-renewal and triploblastic differentiation. Although iPSC use resolved the bioethical issues concerning embryonic human origin, the high rate of teratoma formation on transplantation has impeded their use in regenerative medicine.

MSCs can be easily isolated and expanded in vitro and have been employed in T1D clinical trials (14). Although studies have reported a modest preservation of residual $\beta$ cells after MSCs infusion, prospective long-term studies showing faithful insulin independence are needed (15-17).

Distinctive pluripotent stem cells have been isolated from adult human tissues. Multilineage-differentiating stress-enduring (Muse) cells are stress tolerant and express pluripotency markers $(18,19)$. They are good candidates for treating inflammation as well as altering Th1 lymphocyte activity in an antigen-specific way (20). Infusion of Muse cells attenuated hyperglycemia in an experimental mouse model of T1D (21). 
Allogeneic islet transplantation in severe T1D has become a reliable therapeutic alternative (22). Islet transplantation should achieve precise glycemic control over insulin administration. However, it remains a restricted therapy due to a shortage of cadaveric donors and lack of adequate immunosuppressive regimens (7). Very few transplant patients achieve insulin independence for periods longer than a year (22). To improve functionality along with insulin independence, the use of MSCs to provide a favorable niche for islet engraftment arose as an option to be tested in T1D models (23). Cotransplantation of MSCs and islets ensures the provision of factors that improve long-term islet viability (24). MSCs increase insulin secretion in vitro (25) and improve transplantation outcomes (23). MSCs modulate immune responses by secreting cytokines and soluble factors in the microenvironment $(26,27)$. Immune modulation is key in the context of pancreatic islet allotransplantation, and MSCs help prevent host rejection and nourish the graft $(28,29)$.

MSCs grown as spheroids, meaning a 3D MSCs culture, enhance the secretion of downregulators of the immune response (30, 31), bringing our attention to using this methodology to improve islet allotransplantation in a diabetic mouse model. We describe that spontaneous formation of spheroids confers adult human skin fibroblast-like cell characteristics that improve marginal mass allogeneic islet transplantation in a diabetic mouse model.

The quantitative spheroid-derived cells (SphCs) secretome differs from that of its paired skin fibroblast-like counterparts in containing proteins with putative beneficial effects on islet function and survival. Further studies might determine whether these proteins sustain immunomodulation and cytoprotective effects in transplanted islets. This methodology might contribute to improving transplantation outcome by reducing undesirable consequences of pharmacological immunosuppression as well as the number of islets needed to achieve normoglycemia in T1D recipients.

\section{Materials And Methods}

\section{Mice}

BALB/c, C57BL/6 and BALB/c nude mice (6-9 weeks old) were from the animal care facility (Chemistry Institute; University of São Paulo).

\section{Generation of Spheroid-derived Cells (SphCs) from adult skin fibroblast-like cells}

Abdominal or mammary gland skin pieces were obtained from 3 females (29-46 years old). Skin pieces $(5 \times 5 \mathrm{~mm})$ were treated with 10 $\mu \mathrm{g} / \mathrm{ml}$ collagenase (Serva, Heidelberg). Cells were cultured with DMEM 15\% FBS, $2 \mathrm{mM} \mathrm{L-glutamine,} \mathrm{and} 100 \mu \mathrm{g} / \mathrm{ml}$ streptomycin/ampicillin at $37^{\circ} \mathrm{C} / 5 \% \mathrm{CO}_{2}$ until $7-9$ passages. Cells were plated as hanging drops on an inverted culture dish lid in $30 \mu \mathrm{l}$ of DMEM+FBS at $5 \times 10^{4}$ cells/drop for $72 \mathrm{~h}$ (30). Spheroids were transferred to adherent culture plates, and cells at passages 3-9 were used for experiments. FBSfree conditioned medium was harvested at $48 \mathrm{~h}$.

\section{Surface phenotypic characterization of spheroid-derived cells (SphCs)}

Adult human skin cells and SphCs were harvested using trypsin-EDTA, fixed (2\% PFA) and incubated with fluorochrome-conjugated antibodies: anti-CD105-APC, -CD90-FITC, -CD73-PE, -CD29-PE, -CD34-PE, -CD45-FITC, -HLA-DR-PE and controls, isotype-matched irrelevant monoclonal antibodies: FITC-mlgG1, APC-mlgG1 and PE-mlgG2a (eBioLegend). Analyses were performed by FACSVerse (BD Biosciences) and FlowJo V10 software. At least, $5 \times 10^{4}$ events were acquired per sample (20).

\section{Evaluation of osteogenic, adipogenic and chondrogenic differentiation of spheroid-derived cells (SphCs)}

SphCs were seeded at 70-80\% confluence, cultured in tissue-specific induction medium, fixed and stained, as described previously (20).

\section{Splenocyte assays}

Mice splenocytes were obtained as described (20). Both primary skin fibroblast-like cells $\left(10^{4}\right)$ and SphCs $\left(10^{4}\right)$ were cocultured for 72 $\mathrm{h}$ with $5 \times 10^{5}$ splenocytes activated with anti-CD3 antibody ( $1 \mathrm{mg} / \mathrm{ml}$, eBioscience). A CellTrace Proliferation Kit (Molecular Probes) was used to evaluate T-CD4 ${ }^{+}$proliferation by staining with anti-CD4-APC. Cell media were harvested at $36-72 \mathrm{~h}$, and cytokines were analyzed by FACS using a Cytometric Bead Array Mouse Th1/Th2/Th17 Cytokine Kit (BD Biosciences).

\section{Islets isolation and treatments}

Pancreatic islets were isolated from BALB/c male mice (32). Islets were pretreated for $1 \mathrm{~h}$ with $20 \%$ conditioned medium from skin fibroblasts or SphCs, followed by exposure to a proinflammatory cytokine cocktail (TNFa $8 \mathrm{ng} / \mathrm{ml}$, IFNY $4 \mathrm{ng} / \mathrm{ml}$ and IL- $1 \beta 0.8 \mathrm{ng} / \mathrm{mL}$; PeproTech, USA). After $24 \mathrm{~h}$, islets were labeled with $1 \mu \mathrm{M}$ Newport Green, $1.5 \mu \mathrm{M}$ propidium iodide (PI), and $1 \mu \mathrm{g} / \mathrm{ml}$ Hoechst 33342 . The 
death rate of each islet was considered the PI-positive area (nonviable cells) divided by the total area of the islet. Quantification was evaluated by ImageJ software.

Five islets/well were cultured for $24 \mathrm{~h}$ with $20 \%$ conditioned medium from skin fibroblasts or SphCs. Islets were incubated with Krebs buffer (Sigma-Aldrich) supplemented with $0.2 \%$ BSA and $5.6 \mathrm{mM}$ glucose $/ 30 \mathrm{~min} / 37^{\circ} \mathrm{C}$. The buffer was replaced with Krebs buffer containing $0.2 \% \mathrm{BSA} / 2.8 \mathrm{mM}$ glucose for $1 \mathrm{~h}$. The supernatant was collected, and islets were incubated for $1 \mathrm{~h}$ in $\mathrm{Krebs}$ buffer $(0.2 \%$ BSA/16.7 mM glucose).

\section{Cotransplantation of marginal mass allogeneic islets with spheroid-derived cells (SphCs) in diabetic mice}

Diabetes was induced in C57BL/6 mice by streptozotocin (STZ; i.p., $170 \mathrm{mg} / \mathrm{kg}$ body weight). To establish the islet marginal mass, two different numbers of islet equivalents (IEQs) from BALB/c mice were transplanted under the kidney capsule of diabetic C57BL/6 mice. An IEQ was an islet mass with a diameter of $125 \mu \mathrm{m}$.

Diabetic recipients of marginal mass islets were divided into 4 experimental groups as follows: sham ( $n=12)$, islets (300 IEQ; $n=9)$, 300 IEQ cotransplanted with $1 \times 10^{4}$ skin cells (parental; $n=9$ ) or 300 IEQ cotransplanted with $1 \times 10^{4}$ SphCs (SphCs; $\left.n=10\right)$. Recipients were followed for 10 days to measure nonfasting blood glucose with a glucometer (Contour ${ }^{\mathrm{TM}} \mathrm{TS}$, Bayer). Diabetes was considered after two consecutive blood glucose levels were $\geq 300 \mathrm{mg} / \mathrm{dl}$.

\section{Tumorigenesis assay}

Adult skin cells and SphCs were suspended $\left(1 \times 10^{5}\right.$ in PBS) and i.t. injected into BALB/c nude mice (20). P19 cells were injected (1x10 $)$ as a positive control.

\section{Proteomic sample preparation}

Proteins were concentrated using a $10 \mathrm{kDa}$ filter (Millipore). Concentrate was diluted to $8 \mathrm{M}$ urea/50 mM NH $\mathrm{mCO}_{3}$ and treated with 10 $\mathrm{mM} \mathrm{DTT}$ for $1 \mathrm{~h}$ at $30^{\circ} \mathrm{C}$. Reduced cysteines were alkylated with $55 \mathrm{mM}$ iodoacetamide/50 $\mathrm{mM} \mathrm{NH}_{4} \mathrm{HCO}_{3}$ for 45 min before trypsin (Promega, Madison, WI, USA) digestion at a 1:50 ratio. Tryptic peptides were desalted using Stage Tips with C18 disks (Sigma Aldrich).

\section{Nano LC-MS/MS analysis}

Peptides were suspended in $0.1 \%$ formic acid (FA) before analysis using a nanoflow EASY-nLC ${ }^{\text {TM }}$ II system (Thermo Scientific) coupled to an LTQ-Orbitrap Velos mass spectrometer (Thermo Scientific). Then, the samples were loaded on an Acclaim PepMap C18 (Thermo Germany) trap column ( $2 \mathrm{~cm} \times 100 \mu \mathrm{m}$; inner diameter $5 \mu \mathrm{m})$ and separated onto an Acclaim PepMap C18 (15 cm x $75 \mu \mathrm{m}$; inner diameter $3 \mu \mathrm{m})$ column. A 70 min gradient was used from 100\% mobile phase A (0.1\% FA) to 34\% phase B (0.1\% FA, 95\% ACN), 34\%-95\% at a constant flow rate of $250 \mathrm{nl} / \mathrm{min}$. The mass spectrometer was operated in positive ion mode with data-dependent acquisition. The full scan was acquired in the Orbitrap at 60,000 FWHM resolution in the 400-1600 m/z mass range. Peptide ions were fragmented with CID using a normalized collision energy of 35. Data-dependent acquisition was used to select the 20 most abundant precursor ions for fragmentation. Raw data were accessed in Xcalibur software (Thermo Scientific).

\section{Database searches and bioinformatics analyses}

Raw data were processed using MaxQuant software version 1.5.2.8 and the embedded database search engine Andromeda [PMID: 19029910]. The MS/MS spectra were searched against the UniProt Human (revised) protein database, with the addition of common contaminants, with an MS accuracy of $4.5 \mathrm{ppm}$ and 0.5 Da for MS/MS. Cysteine carbamidomethylation (57.021 Da) was set as the fixed modification, and two missed cleavages were set for trypsin. Methionine oxidation (15.994 Da), protein N-terminal acetylation (42.010 Da) and asparagine and glutamine deamidation (+0.984 Da) were set as variable modifications. Proteins were accepted at FDR less than $1 \%$. Proteins with at least two peptides and two ratio counts were accepted for further validation. Label-free quantification was performed using MaxQuant software with the "match between run" feature activated. Statistical analyses were performed on the Perseus version.1.6.10.43 platform. Contaminants and proteins identified in the reverse database were excluded before the statistical analyses. Analyses were filtered to include peptides identified and quantified in 2 replicates in at least one condition.

Enriched gene ontology (GO) terms (biological processes and molecular functions) for statistically regulated proteins found in the SphC secretome were analyzed using Panther (33). Enriched molecular pathways were analyzed by KEGG (34), Reactome (35) 
and WikiPathways (36) platforms at a threshold of q-value $<0.05$, corrected by Benjamini-Hochberg FDR. Tissue expression analysis was performed using the Human Protein Atlas database (37).

\section{Statistical Analysis}

Data were first analyzed for Gaussian distribution. Differences among groups were compared using two-tailed, nonpaired Student's $t$ test or ANOVA followed by Tukey's posttest. Analyses were performed using GraphPad Prism 5 software (GraphPad Software, Inc., CA). Differences were considered significant at $\mathrm{p} \otimes 0.05$.

\section{Ethics approval and consent to participate}

Mouse studies were approved by the Institutional Care and Use Committee (Comissão de Ética em Uso da Animais do Instituto de Quimica, Universidade de São Paulo (CEUA) n42/2016). All methods were carried out in accordance with relevant guidelines and regulations. All methods are reported in accordance with ARRIVE guidelines.

Human samples were obtained with informed consent according to the Ethics Committee. All methods were carried out in accordance with relevant guidelines and regulations. All experimental protocols were approved by a named institutional and/or licensing Committee. The study protocol was approved by Comité de Ética em Pesquisa do Hospital Universitario da Universidade de São Paulo (CEP-HU/USP 958/09).

\section{Results}

\section{Human skin cell culture in hanging drops generates a three-dimensional structure named spheroids}

Adult human skin cells in adherent plastic showed and maintained a fibroblast-like morphology (Figure $1 \mathrm{~A})$. A total of $5 \times 10^{4}$ skin fibroblastlike cells at $30 \mu \mathrm{l} /$ drop resulted in the optimal initial number of cells for spontaneous spheroid generation. Increasing the cell number generated larger spheroids with necrotic cells inside (data not shown). Figure 1B shows a representative compact spheroid with more than $95 \%$ of healthy (Trypan blue negative) cells reaching an average size between $500-700 \mu \mathrm{m}$ at $72 \mathrm{~h}$. Spheroids were then plated back on adherent plastic dishes, allowing the spontaneous migration of single cells to form a uniform monolayer (Figure 1C). These cells morphologically resembled the original skin primary cells used for spheroid formation, and we named them spheroid-derived cells (SphCs) (Figure 1D).

\section{Characterization of Spheroid-derived Cells (SphCs) from adult skin fibroblast-like cells}

SphCs were immunophenotyped by using fluorochrome-conjugated antibodies against CD29, CD73, CD90 and CD105 followed by flow cytometry analysis. The expression of CD31, CD34, CD45, CD11b and HLA-DR was also evaluated. SphCs gained the expression of surface CD105 (approximately 40\% increment) in comparison with their skin parental cells from which they were generated (Figure 2A). Skin

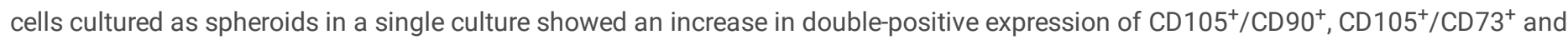

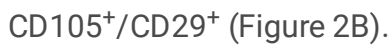

SphCs and skin fibroblast-like cells expressed undetectable or very low levels of HLA-DR, panleukocyte (CD45), hematopoietic progenitor (CD34), monocyte/macrophage (CD11b) and endothelial (CD31) markers (Figure 2C). Therefore, a single culture step of skin fibroblast-like cells as spheroids conferred on SphCs with characteristic surface expression markers of MSCs $(20,38,39)$.

SphCs efficiently differentiated into adipocytes, chondrocytes and osteocytes, as revealed by tissue-specific staining, similar to MSCs (Figure 3A, B). Considering SphCs' characteristics, such as growing on adherent plastic, expressing specific surface antigens and showing multipotent differentiation potential, they truly reach the minimal criteria to define them as MSC-like cells (38).

To investigate their potential as therapeutic tools, we evaluated SphCs by testing their tumorigenic capacity in a favorable environment, such as that offered by immune-compromised mice. Animals were followed up to 180 days postadministration. Tumorigenic P19 cells generated a tumor at 21 days post i.t (not shown). SphCs did not form tumors (Figure 3C), nor was any abnormal tissue observed after histochemical evaluation at 180 days (not shown).

\section{Spheroid-derived cell (SphCs) downmodulate immune responses in vitro}

BALB/c splenocytes were employed to evaluate SphCs immune regulatory capacity (40). Anti-CD3-stimulated T lymphocyte proliferation was compared under the influence of SphCs or, alternatively, their skin fibroblast-like counterparts. There was a reduction in T-CD $4^{+}$ 
lymphocyte proliferation when these cells were cocultured with SphCs, while the presence of skin fibroblast-like cells did not alter proliferation rates (Figure 4A).

We analyzed the profile of cytokines secreted by lymphocytes stimulated with anti-CD3 in the presence of SphCs in vitro. Cytokines were quantified by flow cytometry in the $36 \mathrm{~h}$-spent supernatant of anti-CD3-primed splenocytes cocultured with either skin fibroblast-like cells or, alternatively, SphCs. The hallmark Th1 cytokine INF-g was dramatically downregulated by the presence of both SphCs and skin fibroblastlike cells (Figure 4B). Relevant cytokines required to mount an effective proinflammatory response, such as IL-2, IL-6, and TNF-a, were less abundant in the supernatant derived from both skin fibroblast-like cells and SphCs than in the positive control (anti-CD3 alone), and the levels were even lower in the presence of SphCs (Figure 4C, D, E). IL-4 favors the induction of a Th2 lymphocyte profile (41). SphCs induced a 4-fold increase in the secretion of IL-4 in comparison with anti-CD3 stimulation, while skin fibroblast cells did not show any effect (Figure 4F). Regarding IL-10, a classic immune-modulatory cytokine, SphCs did not stimulate its secretion after CD3 activation (Figure 4G). There were no differences in the secretion of IL-17A between cocultures and the control (not shown).

Taking into account the proliferation and cytokine profile of T-CD $4^{+}$lymphocytes, SphCs are capable of inducing a bias toward a decrease in the ratio of Th1/Th2 lymphocytes, supporting an anti-inflammatory environment.

\section{Spheroid-derived cell (SphC)-conditioned media attenuates proinflammatory cytokine-induced islet death}

Islets cultured with a cocktail of proinflammatory cytokines, mimicking the unfavorable microenvironment to which they are exposed during the autoimmune process of T1D, die by apoptosis (42-45). We assessed whether soluble factors secreted by SphCs might protect isolated islets from the proinflammatory damage exerted by cytokines. After $24 \mathrm{~h}$, the cocktail of proinflammatory cytokines induced a 4 -fold increase in islet death relative to the control (islets in optimal conditions, e.g., 10\% FBS). SphCs supernatants containing soluble factors reduced islet death in comparison with proinflammatory cytokine stimuli (approximately $50 \%$ reduction). There was a lack of beneficial effect on islet survival employing conditioned media from skin fibroblast-like cells (Figure 5A).

Conditioned media from both SphCs and skin fibroblast-like cells did not perturb glucose-stimulated insulin secretion or total islet-insulin content, indicating that soluble factor/s would only affect islet survival (Figure 5B;C).

\section{Cotransplantation of marginal mass allogeneic islets with SphCs improves glycemic control in diabetic mice}

We established the marginal mass of allogeneic islets using 300 IEQ transplanted under the kidney capsule of diabetic C57BL/6 mice. Transplantation of 300 IEQ maintained glycemic levels slightly below those of sham-operated mice (Figure $6 \mathrm{~A}$ ). As a control, engraftment of 600 IEQ from BALB/c mice into C57BL/6 diabetic mice dramatically decreased glycemia as soon as 1 day postadministration (not shown). Figure 6B shows animal weights throughout the experimental period. The marginal mass of allogeneic islets contributed to the maintenance of body weight, while diabetic surgical sham animals lost significant body weight (Figure 6B). Cotransplantation of the marginal mass of allogeneic islets with SphCs $\left(10^{4}\right)$ improved glycemia soon after administration compared with other experimental groups (Figure 6C).

\section{Spheroid-derived cells (SphCs) protein secretome analysis}

Having established that conditioned media of SphCs both immunomodulate T-CD $4^{+}$lymphocyte responses and exert cytoprotection on cytokine-challenged islets, we analyzed the protein secretome of SphCs and primary skin fibroblast-like cells using a comparative proteomic approach. After comparing the abundance of proteins present in both secretomes, we classified protein components identified in three different groups according to the ratio of abundance in the secretome of SphCs versus the one obtained in the corresponding primary skin culture. We established a cutoff value $\geq 1.5$ or $\leq 0.65$ for more abundant and less abundant proteins, respectively. Tables 1 and 2 (Suppl. material) summarize the protein components of SphCs presenting an increase (upregulated) or decrease (downregulated) in relative abundance when compared with the corresponding skin fibroblast-like cells. Approximately $33 \%$ of the proteins were upregulated in the SphC secretome, while almost $46 \%$ of them were downregulated.

Additionally, each set of identified proteins was submitted to interactome analysis to understand their putative cellular functions (Figure 7 , Suppl. Tables 3 and 4). Among the underexpressed proteins, we identified proteins related to extracellular matrix remodeling (e.g., actin, laminin, tubulin, collagen, elastin, lumican, SPARC and thrombospondina-1), collagen formation, complement C1-related proteins, others associated with elastic fibers (elastin and other proteins), and glycosaminoglycan metabolism (which have functions in the regulation of cell growth, proliferation, promotion of cell adhesion and anticoagulation).

Among the upregulated proteins, there were Rho GTPases that coordinately activate several transduction pathways, proteins involved in glucose uptake and its metabolism (GLUT4, enolases), regulation of apoptosis (e.g., 14-3-3) and other mechanisms involved in cellular

Page 6/25 
development, cell survival (e.g., gremlin) and stress response (pentraxin-3), and migfilin, which regulates remodeling, morphology and motility processes.

In summary, this protein secretome analysis highlights the expression pattern of proteins secreted by SphCs that might be responsible for islet survival, acceleration of glucose metabolism, and tissue repair.

\section{Discussion}

In persons with T1D, most of their b cells are selectively destroyed, and some may remain dedifferentiated (46). Exogenous insulin administration schemes often fail to maintain fine-tuned glycemic control, which may lead to frequent unwarned hypoglycemic/hyperglycemic episodes associated with side effects and death risk. Transplantation of whole solid pancreas or isolated islets from cadaveric donors constitutes valid options to achieve insulin independence and/or diminish glycemia fluctuations. Pancreas transplantation is considered invasive and is often associated with comorbidities (47). Therefore, transplantation of isolated islets is presented as an appealing therapeutic option for labile T1D patients. The accessibility of islet transplantation as a wider therapeutic intervention is very limited due to a shortage of cadaveric donors and the existence of few centers worldwide with adequate expertise (https://citregistry.org/home).

Efforts in clinical research have contributed significantly to improving islet transplantation, achieving exogenous insulin independence in $50 \%$ of patients after 5 years of multidonor infusions. The latter constitutes a success rate similar to that of organ pancreas transplantation (48). These patients manifested a reduced frequency of hypoglycemic events.

Preservation of islet viability during and after isolation remains challenging because of a significant loss of functionality during islet preinfusion due to both mechanical and oxidative stress as well as activation of apoptotic pathways $(49,50)$. Therefore, novel procedures toward maintenance of islet viability and normal functionality before and after infusion will improve islet transplantation outcomes to efficiently treat many more people with labile T1D. In this scenario, cotransplantation of stem cells together with isolated islets has been investigated as a putative translational option for T1D. MSCs have been noted because of their anti-inflammatory, angiogenic and immune-regulatory capacities as well as their source of nourishing factors for islets $(28,51-53)$. Cotransplantation of MSCs with islets improved their survival and function in experimental diabetic mice using syngeneic and allogeneic settings and in immune-deficient mice $(21,28,54-56)$.

MSCs possess the capacity to repair or attenuate tissue destruction by paracrine secretions or cell-to-cell contacts modulating inflammatory and immune reactions $(11,57)$. MSCs possess the capacity to repair tissues or attenuate destructive processes by paracrine secretion of cytokines as well as other factors, some of which have already been identified, such as tumor necrosis factor-inducible gene 6 (TSG-6) and stanniocalcin-1 (STC-1), which are able to decrease both inflammation and immune responses $(30,58)$. Furthermore, MSCs cultured as spheroids increase the surface expression of CXCR4 and adhesion to endothelial cells (58). Based on these reports and taking into account that obtaining skin tissue from adult humans is safe and minimally invasive, we set out to evaluate whether adult human skin fibroblast-like cells after aggregation in culture could acquire the aforementioned characteristics and thus contribute to improving islet transplantation outcomes in diabetic mice.

We describe a culture procedure that confers fibroblast-like cells obtained from adult human skin properties that improve marginal mass allogeneic islet transplantation in experimental diabetic mice. These results highlighted that the beneficial effects of cotransplantation of SphCs with marginal mass allogeneic islets could be due to its influence on the facilitation of islet engraftment and, inderectly, in the attenuation of the host's alloimmune response. The observed overall increase in islet cell viability finally led to better glycemic control in diabetic transplanted mice.

Adult human skin fibroblast-like cells cultured for $72 \mathrm{~h}$ as hanging drops formed spheroids of $\sim 500 / 700 \mu \mathrm{m}$ in diameter and composed of more than $95 \%$ living cells, similar to what has been reported using bone marrow (30). These cells spontaneously aggregated under gravity when cultured in hanging drops without the addition of any specific growth factor. We believe that the phenomenon of aggregation facilitates cell-to-cell contacts that might aid in maintaining the stemness of SphCs, as has already been demonstrated using 3D culture of $\operatorname{MSCs}(59,60)$.

Spontaneously migrating cells from spheroids, e.g., SphCs, expanded in adherent plastic and retained the capacity to differentiate after induction in adipocytes, osteocytes and chondrocytes, similar to conventional MSCs. SphCs gained the expression of several CDs distinctive of MSCs (i.e., CD29/CD73/CD90 and CD105) with very low or absolute lack of expression of CD11b, CD31, CD34, CD45 and CD34 surface molecules (39). Since we found no expression of HLA-DR molecules on the surface of SphCs, they may remain undetectable to allogeneic effector T-CD4+ lymphocytes, as already reported in other studies using different sources of cells (61). After several months of 
SphCs administration, they did not show proliferation, maldifferentiation, or teratoma formation in immunodeficient mice. These last characteristics position SphCs as a very safe alternative with potential therapeutic use.

SphCs have immunoregulatory properties similar to MSCs (62). Our studies offer new insights into the immunomodulatory capacities of SphCs, focusing on their ability to diminish T-CD $4^{+}$cell proliferation and biasing the cytokine profile of stimulated splenocytes toward an increase in the Th2/Th1 ratio in vitro. We have previously described potent immunomodulatory features of a unique human stem cell population called multilineage-differentiating stress-enduring (Muse) cells derived from adipose tissue (20). Muse cells and ShpCs have the ability to grow in suspension as spheroids. Therefore, aggregation of cells forming clusters might be a key driving force to make cells express cytokines and soluble factors such as TGF-b1 released by Muse cells as prominent mediators of their immunomodulatory actions (20).

In vitro downmodulation of splenocytes by SphCs was much more effective than their primary skin counterparts, which indicates that a single culture step as a spheroid is sufficient to acquire such properties. We observed that SphCs significantly diminished the secretion of classic proinflammatory cytokines (IFN-g, IL-2, IL-6 and TNF-a) while increasing IL-4 (a Th2-hallmark cytokine) by activated splenocytes. Comparably, it was reported that MSCs grown as spheroids showed anti-inflammatory capacity and converted macrophages to an M2 phenotype through the expression of TSG-6 or prostaglandin E2 $(30,63,64)$.

CD73 has ecto-5'-nucleotidase activity, which may change extracellular media, influencing immune responses such as inducing immune tolerance and $\mathrm{T}$ lymphocyte differentiation and tilting the balance toward immune-suppressive microenvironments $(65,66)$. Skin fibroblastlike cells cultured as spheroids gained surface expression of CD73 (60\% increase vs primary skin cells, approximately; Fig. 2B). Extensive nucleotidase activity on the surface of SphCs might increase nucleoside concentrations and ultimately inhibit the proliferation and activation of allogeneic effector T lymphocytes (67).

Antigen-specific T lymphocytes are involved in the autoimmune process that destroys b cells in T1D (68). The early stages of the disease mobilize inflammatory infiltration into the islets with accumulation of immune cells in and around the islets (insulitis) (69), all of which contribute to b cell dysfunction and destruction (70). Proinflammatory cytokines secreted by infiltrated immune cells, such as IL-1b, IFN$\mathrm{g}$ and TNF-a, impair the function and viability of pancreatic b cells (71).

We found that SphC conditioned media promoted cell death inhibition (approximately 50\%) in isolated islets when they were challenged by a mixture of proinflammatory cytokines in vitro. Studies have confirmed that growth factors secreted by MSCs, such as VEGF, EGF and HGF $(72,73)$, may conserve islet integrity, growth and functionality. However, the mechanisms by which these factors are protective for b cells under cytokine injury are still unclear. They might act through classic regulators of b cell proliferation, such as Akt and Erk (74).

Whether SphCs conditioned media may influence cell proliferation and/or regeneration of b cells might require prolonged culture periods of islets. Likewise, we did not observe improvements in basal insulin secretion or glucose-stimulated insulin secretion in islets exposed to SphCs conditioned media.

Transplanted islets encounter a rapid attack mediated by allogeneic destructive reactions after infusion (75-77). For all allogeneic forms of transplantation, antigen-presenting cells (APCs) infiltrating the graft become fully matured by the action of locally released proinflammatory mediators, ischemia and necrotic cells. Matured APCs migrate to secondary lymphoid organs where they stimulate the proliferation of both alloreactive $\mathrm{T}$ and recipient $\mathrm{T}$ cells recognizing allogeneic MHCs and allopeptides, respectively. These two populations of T cells mount the allo-response against the islets. Thus, the need for lifelong treatment to avoid rejection of allogeneic islets is mandatory and involves difficult management (78). The addition of MSCs at the site of transplantation may help immune tolerance and protect islets, avoiding the administration of high doses of toxic immunosuppressive drugs. We found that cotransplantation of marginal mass allogeneic islets with SphCs improved glycemic control in STZ-induced diabetic mice. We speculate that the success of this procedure is due in part to the local release of pro-survival factors impacting directly on islets, along with creating a favorable anti-inflammatory microenvironment. Added to this last situation is the immune-regulatory activity exerted by SphCs that keep alloreative $T$ lymphocytes under control. All these features are therefore believed to be relevant for the beneficial effects observed in this T1D mouse model (14). The fact that infusing marginal mass allogeneic islets together with SphCs improves glycemia in diabetic mice but does not reach normal glucose levels may be attributable to an insufficient number ( $10^{4}$ cells) of administered SphCs. Similar experiments employing a mixture of MSCs and islet-derived single cells at a 1:1 ratio transplanted in a mouse model of T1D reached lasting normoglycemia (55). Considering an estimated $\sim 1500$ cells in an islet ( $₫ 150$ m diameter) (79), we cotransplanted SphCs:Islet-cells at a 1:45 ratio. Future experiments, increasing the aforementioned ratio at least 10 times, could improve the results obtained.

As soluble factors secreted by SphC have a favorable impact on the survival and functionality of islets, we hypothesized that proteins secreted differently by cells after aggregation as spheroids could be responsible for the beneficial effects observed on $\beta$ cell viability.

Page $8 / 25$ 
Therefore, we set out to identify proteins/peptides secreted by them. Protein secretome studies revealed that several biological processes and intracellular pathways were differentially regulated between SphCs and skin fibroblast-like cell-conditioned media (Figure 7). Within these pathways, we identified proteins that could target processes associated with $b$ cell cytoprotection together with modulating immune responses. SphCs regulated approximately $70 \%$ of the proteins identified in the secretome compared with skin fibroblast-like cells.

The top hits on the functions displayed by these proteins were related to extracellular matrix remodeling, modulation of apoptosis and cell differentiation. It has been reported that low levels of some matrix metalloproteases might lead to an increased activity of membrane-bound FASL. Consequently, one might expect augmented apoptotic capacity by FASL-expressed SphCs on effector T-cells without affecting the viability of Treg lymphocytes, both contributing to a significant increase in b cell viability and islet graft lifespan $(80,81)$. We found that inhibitors of metalloproteases were upregulated in the SphCs secretome and could, partially, contribute to the less aggressive proinflammatory microenvironment created when these cells were cocultured with murine splenocytes.

The protein 14-3-3ろ, also upregulated in the SphCs secretome, has been implicated in the inhibition of b cell apoptosis induced by different stimuli (82). Both Gremlin-1 and pentatraxin-3, which are abundant in the secretome of SphCs, have been related to growth and survival in response to inflammation and tissue damage (83-86). There is no knowledge about gremlin-1 in the context of $b$ cell biology. In tubular epithelial cells, gremlin-1 increased TFG-b production through Smad activation, inducing a myofibroblast-like phenotype (87).

Taken together, these results highlight the underscored ability of SphC to create a favorable niche for allo-islet reception, preserving islet viability and functionality and reducing the need for immune-suppressive drugs.

The possibility of using conditioned media from SphCs or a combination of factors identified in the secretome study could provide the flexibility of an off-the-shelf product for wider clinical applications. These proteins could be prepared as supplements to include in the cultured media at the time of transplantation and simply comixed with islets for delivery without the need to encapsulate or chemically modify the islets. Further innovations in culture conditions to generate more efficient SphCs as adjuvants of islet engraftment will move the islet transplant field closer to insulin independence by providing islets with increased cytoprotection and overcoming the requirement of risky chemotherapy for immune suppression.

\section{Conclusion}

As islet transplantation for T1D patients remains an ineffective procedure requiring up to 5 different islet infusions associated with loss of functionality and the use of cytotoxic drugs, appropriate employment of cotransplantation with SphCs would be highly advantageous. The use of skin cells to generate SphCs is free of ethical concerns, avoiding the need for genetic cell modifications associated with considerable technical, ethical and regulatory challenges. Moreover, our results establish evidence of a translatable and potentially more effective immune-modulatory strategy with improved islet viability. Thus, it contributes to tackling the problem of organ donor scarcity.

\section{Abbreviations}

T1D

Type 1 diabetes

MSC

Mesenchymal stem cells

SphCs

spheroid-derived cells

ES

Embryonic stem

iPSCs

Induced pluripotent stem cells

Muse

Multilineage-differentiating stress-enduring

STZ

Streptozotocin

IEQ

islets equivalent

GO

Gene ontology 
TSG-6

tumor necrosis factor-inducible gene 6

STC-1

stanniocalcin-1

APC

Antigen-presenting cells

PBS

Phosphate-buffered saline

\section{Declarations}

Acknowledgments

The technical assistance of Z. de Mendonça, D. Costa, S. R. Souza and M. N. Silva.

\section{Consent for publication}

Not applicable.

\section{Data Availability Statement}

Raw data can be available upon request.

\section{Competing interests}

The authors declare that they have no competing interests.

\section{Funding Statement}

This work was supported by FAPESP [grants 12/16785-4, 13/07029-4, 12/50680-5 and 13/07937-8], CAPES [AUX-PE-PROBITEC-908/2012], CNPq [grant 141529/2012-1] and Fundación Marjorie para la Investigación en Diabetes (FuMDiab-Argentina) and ANPCyTArgentina/PICT2018.

\section{Author contribution:}

Talita C. de Oliveira: conception and design; data analysys and interpretation; performed experiments.

Maria F. Forni: provision of study material, data analysis; interpretation

Ancély F. Santos: performed experiments; data analysis

Luz Andreone: performed experiments; data analysis

Rosangela A.M. Wailemann: performed experiments; data analysis

Leticia F. Terra: performed experiments; data analysis

Vinicius M. Gomes: performed experiments; data analysis

Mari C. Sogayar: data analysis and contributed to discussion

Janaina Macedo da Silva: secretome analysis, corresponding figure and its interpretation

Livia Rosa-Fernandes: secretome analysis, corresponding figure and its interpretation

Giuseppe Palmisano: secretome analysis, corresponding figure and its interpretation

Leticia Labriola: conception and design; financial support; data analysis and interpretation; manuscript writing; final approval of manuscript Marcelo J. Perone: conception and design; financial support; data analysis and interpretation; manuscript writing; final approval of manuscript 


\section{References}

1. Bluestone, J. A., Herold, K. \& Eisenbarth, G. Genetics, pathogenesis and clinical interventions in type 1 diabetes. Nature, 464, 1293-1300 (2010).

2. Saeedi, P. et al. Global and regional diabetes prevalence estimates for 2019 and projections for 2030 and 2045 : Results from the IDF Diabetes Atlas, 9th edition. Diabetes Res Clin Pract 2019; 157:107843

3. Stiller, C. R. et al. Effects of cyclosporine immunosuppression in insulin-dependent diabetes mellitus of recent onset., 223, 1362-1367 (1984).

4. Bougneres, P. F. et al. Limited duration of remission of insulin dependency in children with recent overt typel diabetes treated with lowdose cyclosporin., 39, 1264-1272 (1990).

5. Keymeulen, B. et al. Insulin needs after CD3-antibody therapy in new-onset type 1 diabetes. N Engl J Med, 352, 2598-2608 (2005).

6. Shapiro, A. M. et al. Islet transplantation in seven patients with type 1 diabetes mellitus using a glucocorticoid-free immunosuppressive regimen. New Engl J Med, 343 (4), 230-238 (2000).

7. Schuetz, C. et al. IPITA YIC Young Investigator Committee. $\beta$ Cell Replacement Therapy: The Next 10 Years. Transplantation, 102 (2), 215-229 (2018).

8. Barton, F. B. Collaborative Islet Transplant Registry (CITR) update. Paper presented at: IPITA, IXA, CTS Joint Congress; November 16, 2015; Melbourne, Australia.

9. Senior, P., Kin, T., Shapiro, J. \& Koh, A. Islet transplantation at the University of Alberta: status update and review of progress over the last decade. Can J Diabetes, 36 (1), 32-37 (2012).

10. Calafiore, R. \& Basta, G. Stem cells for the cell and molecular therapy of type 1 diabetes mellitus (T1D): the gap between dream and reality. Am J Stem Cells, 4, 22-31 (2015).

11. Uccelli, A., Moretta, L. \& Pistoia, V. Mesenchymal stem cells in health and disease. Nat Rev Immunol, 8, 726-736 (2008).

12. Thomson, J. A. et al. Embryonic stem cell lines derived from human blastocysts., 282, 1145-1147 (1998).

13. Takahashi, K. \& Yamanaka, S. Induction of pluripotent stem cells from mouse embryonic and adult fibroblast cultures by defined factors., 126, 663-676 (2006).

14. Cho, J. et al. A review of clinical trials: mesenchymal stem cell transplant therapy in type 1 and type 2 diabetes mellitus. Am $J$ Stem Cells, 7 (4), 82-93 (2018).

15. Carlsson, P-O. et al. Preserved $\beta$-cell function in type 1 diabetes by mesenchymal stromal cells., 64, 587-592 (2015).

16. Mesples, A. et al.. Early immunotherapy using autologous adult stem cells reversed the effect of anti-pancreatic islets in recently diagnosed type 1 diabetes mellitus: Preliminary results. Med Sci Monit. 2013; 19:852-857.

17. Li, L. et al. Infusion with Human Bone Marrow-derived Mesenchymal stem cells Improves $\beta$-cell function in patients and nonobese mice with severe diabetes. Sci Rep, 6, 37894 (2016).

18. Kuroda, Y. et al. Unique multipotent cells in adult human mesenchymal cell populations. Proc Natl Acad Sci USA, 107, 8639-8643 (2010).

19. Wakao, S. et al. Multilineage-differentiating stress-enduring (Muse) cells are a primary source of induced pluripotent stem cells in human fibroblasts. Proc Natl Acad Sci USA, 108, 9875-9880 (2011).

20. Gimeno, M. L. et al. Pluripotent nontumorigenic adipose tissue-derived Muse cells have immunomodulatory capacity mediated by TGFß1. Stem Cells Translational Medicine, 6, 161-173 (2017).

21. Perone, M. J., Gimeno, M. L. \& Fuertes, F. Immunomodulatory properties and potential therapeutic benefits of Muse cells administration in diabetes. In: Muse cells, endogenous reparative pluripotent stem cells. Adv. Exp. Med. Biol, 1103, 115-129 (2018).

22. Piemonti, L. \& Pileggi, A. 25 years of the ricordi automated method for islet isolation. CellR4, 1, 8-22 (2013).

23. Montanari, E. et al. Multipotent mesenchymal stromal cells enhance insulin secretion from human islets via N-cadherin interaction and prolong function of transplanted encapsulated islets in mice. Stem Cell Res. Ther, 8 (1), 199 (2017).

24. Jung, E-J. et al. Bone marrow-derived mesenchymal stromal cells support rat pancreatic islet survival and insulin secretory function in vitro., 13, 1929 (2011).

25. Wang, R. \& Rosenberg, L. Maintenance of beta-cell function and survival following islet isolation requires re-establishment of the isletmatrix relationship. J. Endocrinol, 163, 181190 (1999).

26. Soleymaninejadian, E., Pramanik, K. \& Samadian, E. Immunomodulatory properties of mesenchymal stem cells: cytokines and factors. Am J Reprod Immunol, 67, 1-8 (2012).

Page $11 / 25$ 
27. Rasmusson, I. Immune modulation by mesenchymal stem cells. Exp Cell Res, 312, 2169-2179 (2006).

28. Rackham, C. L. et al. Cotransplantation of mesenchymal stem cells maintains islet organization and morphology in mice., 54, 11271135 (2011).

29. Ito, T. et al. Mesenchymal stem cell and islet cotransplantation promotes graft revascularization and function., 89, 1438-1445 (2010).

30. Bartosh, T. J. et al. Aggregation of human mesenchymal stromal cells (MSCs) into 3D spheroids enhances their antiinflammatory properties. Proc Natl Acad Sci U S A, 107, 13724-13729 (2010).

31. Bartosh, T. J. et al. Dynamic compaction of human mesenchymal stem/precursor cells into spheres self-activates caspase-dependent IL1 signaling to enhance secretion of modulators of inflammation and immunity (PGE2, TSG6, and STC1)., 31, 2443-2456 (2013).

32. Wailemann, R. A. et al. Heat shock protein B1 is required for the prolactin-induced cytoprotective effects on pancreatic islets. Mol Cell Endocrinol, 477, 39-47 (2018).

33. Mi, H. et al. PANTHER version 14: more genomes, a new PANTHER GO-slim and improvements in enrichment analysis tools. Nucleic acids research, 47 (D1), D419-d426 (2019).

34. Kanehisa, M. \& Goto, S. KEGG: Kyoto Encyclopedia of Genes and Genomes. Nucleic acids research, 28 (1), $27-30$ (2000).

35. Jassal, B. et al. The reactome pathway knowledgebase. Nucleic acids research, 48 (D1), D498-d503 (2020).

36. Slenter, D. N. et al. WikiPathways: a multifaceted pathway database bridging metabolomics to other omics research. Nucleic acids research, 46 (D1), D661-D667 (2017).

37. Uhlén, M. et al. Proteomics. Tissue-based map of the human proteome, Science (New York, N.Y.) 347(6220) 2015;1260419.

38. Dominici, M. et al. Minimal criteria for defining multipotent mesenchymal stromal cells. The International Society for Cellular Therapy position statement Cytotherapy, 8 (4), 315-317 (2006).

39. Chase, L. G. et al. Development and Characterization of a Clinically Compliant Xeno-Free Culture Medium in Good Manufacturing Practice for Human Multipotent Mesenchymal Stem Cells. Stem Cells Transl Med, 1, 750-758 (2012).

40. Castro, C. N. et al. Curcumin ameliorates autoimmune diabetes. Evidence in accelerated murine models of type 1 diabetes. Clin Exp Immunol, 177, 149-160 (2014).

41. Fallon, P. G. et al. IL-4 induces characteristic Th2 responses even in the combined absence of IL-5, IL-9, and IL-13., 17, 7-17 (2002).

42. Ortis, F. et al. Induction of nuclear factor-kappaB and its downstream genes by TNF-alpha and IL-1beta has a pro-apoptotic role in pancreatic beta cells., 51, 1213-1225 (2008).

43. Mizuno, N. et al. Altered bcl-2 and bax expression and intracellular Ca2+ signaling in apoptosis of pancreatic cells and the impairment of glucose-induced insulin secretion., 139, 1429-1439 (1998).

44. Kim, K-A. \& Lee, M-S. Recent progress in research on beta-cell apoptosis by cytokines. Front Biosci (Landmark Ed), 14, 657-664 (2009).

45. Mandrup-Poulsen, T. et al. Affinity-purified human Interleukin I is cytotoxic to isolated islets of Langerhans., 29, 63-67 (1986).

46. Atkinson MA, Eisenbarth GS, Michels AW. Type 1 diabetes.Lancet2014; 383(9911):69-82.

47. Shapiro, A. M. J., Pokrywczynska, M. \& Ricordi, C. Clinical pancreatic islet transplantation. Nat Rev Endocrinol, 13, 268-277 (2017).

48. Barton, F. B. et al. Improvement in outcomes of clinical islet transplantation: 1999-2010. Diabetes Care, 35 (7), 1436-1445 (2012).

49. Bottino, R. et al. Preservation of human islet cell functional mass by anti-oxidative action of a novel SOD mimic compound., 51, 25612567 (2002).

50. Kin, T. et al. Risk factors for islet loss during culture prior to transplantation. Transpl Int, 21, 1029-1035 (2008).

51. Yoshimatsu, G. et al. The co-transplantation of bone marrow derived mesenchymal stem cells reduced inflammation in intramuscular islet transplantation. PLoS One, 10, e0117561 (2015).

52. Hayward, J. A. et al. Co-transplantation of mesenchymal stem cells with neonatal porcine islets improve graft function in diabetic mice., 66, 1312-1321 (2017).

53. Park, K. S. et al. Trophic molecules derived from human mesenchymal stem cells enhance survival, function, and angiogenesis of isolated islets after transplantation., 89, 509-517 (2010).

54. Borg, D. J. et al. Mesenchymal stromal cells improve transplanted islet survival and islet function in a syngeneic mouse model., 57, 522-531 (2014).

55. Westenfelder, C. et al. Durable control of autoimmune diabetes in mice achieved by intraperitoneal transplantation of "neo-islets", threedimensional aggregates of allogeneic islet and "mesenchymal stem cells". Stem Cells Trans/ Med, 6 (7), 1631-1643 (2017).

56. Rackham, C. L. et al. Preculturing islets with adipose-derived mesenchymal stromal cells is an effective strategy for improving transplantation efficiency at the clinically preferred intraportal site. Cell Med, 7, 37-47 (2014). 
57. Nauta, A. J. \& Fibbe, W. E. Immunomodulatory properties of mesenchymal stromal cells., 110, 3499-3506 (2007).

58. Wisniewski, H. G. \& Vilcek, J. Cytokine-induced gene expression at the crossroads of innate immunity, inflammation and fertility: TSG-6 and PTX3/TSG-14. Cytokine Growth Factor Rev, 15, 129-146 (2004).

59. Potapova, I. A. et al. Culturing of human mesenchymal stem cells as three-dimensional aggregates induces functional expression of CXCR4 that regulates adhesion to endothelial cells. J Biol Chem, 283, 13100-13107 (2008).

60. Stiehler, M. et al. Effect of dynamic 3-D culture on proliferation, distribution, and osteogenic differentiation of human mesenchymal stem cells. J Biomed Mater Res A, 89, 96-107 (2009).

61. Gotherstrom, C. et al. Fetal and adult multipotent mesenchymal stromal cells are killed by different pathways., 13, 269-278 (2011).

62. Melief, S. M., Geutskens, S. B., Fibbe, W. E. \& Roelofs, H. Multipotent stromal cells skew monocytes toward an anti-inflammatory function: the link with key immunoregulatory molecules. Hematologica, 98, e121-2 (2013).

63. Ylöstalo, J. H. et al. Human mesenchymal stem/stromal cells cultured as spheroids are self-activated to produce prostaglandin E2 that directs stimulated macrophages into an anti-inflammatory phenotype. STEM CELLS, 30, 2283-2296 (2012).

64. Nemeth, K. et al. Bonemarrowstromal cells attenuate sepsis via prostaglandin $\mathrm{E}(2)$-dependent reprogramming of host macrophages to increase their interleukin-10 production. Nat Med, 15, 42-49 (2009).

65. Silva-Vilches, C. et al. Production of extracellular adenosine by CD73(+) dendritic cells is crucial for induction of tolerance in contact hypersensitivity reactions. J Invest Dermatol, 139 (3), 541-551 (2019).

66. Bono, M. R. et al. CD73 and CD39 ectonucleotidases in T cell differentiation: Beyond immunosuppression. FEBS Lett, 589 (22), $3454-$ 3460 (2015).

67. Kepp, O. et al. Extracellular nucleosides and nucleotides as immunomodulators. Immunol Rev, 280 (1), $83-92$ (2017).

68. Roep, B. O. \& Kallan, A. A. Beta-cell antigen-specific lysis of macrophages by CD4 T-cell clones from newly diagnosed IDDM patients. A putative mechanism of T-cell-mediated autoimmune islet cell destruction., 41, 1380-1384 (1992). De Vries RR

69. Barcala Tabarrozzi, A. E. et al. Cell-based interventions to halt autoimmunity in type 1 diabetes mellitus. Clinical and Experimental Immunology, 171, 135-146 (2013).

70. Eizirik, D. L., Colli, M. L. \& Ortis, F. The role of inflammation in insulitis and beta-cell loss in type 1 diabetes. Nat Rev Endocrinol, 5 (4), 219-226 (2009).

71. Berchtold, L. A. et al. Cytokines and Pancreatic beta-Cell Apoptosis. Adv Clin Chem, 75, 99-158 (2016).

72. Gnecchi, M. et al. Paracrine mechanisms in adult stem cell signaling and therapy. Circ. Res, 103, 1204-1219 (2008).

73. Otonkoski, T. et al. A role for hepatocyte growth factor/sactter factor in fetal mesenchyme-induced pancreatic beta-cell growth., 137 (7), 3131-3139 (1996).

74. Gao, X. et al. Bone marrow mesenchymal stem cells promote the repair of islets from diabetic mice through paracrine actions. Mol Cell Endocrinol, 388 (1-2), 41-50 (2014).

75. Bennet, W. et al. Incompatibility between human blood and isolated islets of Langerhans: a finding with implications for clinical intraportal islet transplantation? Diabetes 1999; 48:1907-1914

76. Morelli, A. E. \& Thomson, A. W. Dendritic cells: regulators of alloimmunity and opportunities for tolerance induction. Immunol Rev, 196, 125-146 (2003).

77. Bellin, M. D. et al. Potent induction immunotherapy promotes long-term insulin independence after islet transplantation in type 1 diabetes. Am J Transplant, 12 (6), 1576-1583 (2012).

78. Hering, B. J. et al. Phase 3 Trial of Transplantation of Human Islets in Type 1 Diabetes Complicated by Severe Hypoglycemia. Diabetes Care, 39 (7), 1230-1240 (2016).

79. Pisania, A. et al. Quantitative analysis of cell composition and purity of human pancreatic islet preparations. Lab Invest, 90 (11), 16611675 (2010).

80. Headen, D. M. et al. Local immunomodulation Fas ligand-engineered biomaterials achieves allogeneic islet graft acceptance. Nat Mater, 17, 732-739 (2018).

81. Yolcu, E. S. et al. Pancreatic islets engineered with SA-FasL protein establish robust localized tolerance by inducing regulatory T cells in mice. J Immunol, 187, 5901-5999 (2011).

82. Lim, G. E., Piske, M. \& Johnson, J. D. 14-3-3 proteins are essential signaling hubs for beta cell survival., 56, 825-837 (2013).

83. Xiang, Q. et al. Overexpression of Gremlin1 in Mesenchymal Stem Cells Improves Hindlimb Ischemia in Mice by Enhancing Cell Survival. J Cell Physiol, 232, 996-1007 (2017). 
84. Hong, D. et al. Gremlin1 Delivered by Mesenchymal Stromal Cells Promoted Epithelial-Mesenchymal Transition in Human Esophageal Squamous Cell Carcinoma. Cell Physiol Biochem, 47, 1785-1799 (2018).

85. Deban, L. et al. Pentraxins in innate immunity: lessons from PTX3. Cell Tissue Res, 343, 237-249 (2011).

86. Cappuzzello, C. et al. Mesenchymal Stromal Cell-Derived PTX3 Promotes Wound Healing via Fibrin Remodeling. J Invest Dermatol, 136, 293-300 (2016).

87. Rodrigues-Diez, R. et al. Gremlin activates the Smad pathway linked to epithelial mesenchymal transdifferentiation in cultured tubular epithelial cells. Biomed Res Int, 2014, 802841 (2014).

\section{Tables}

Table 1. Up-regulated proteins in the SphCs cells (spectral count SphCs/ Parental skin cells $\geq 1.5$ folds ) 


\begin{tabular}{|c|c|c|c|c|c|c|c|c|c|}
\hline Accession & Description & $\begin{array}{l}\text { Gene } \\
\text { name }\end{array}$ & Score & $\begin{array}{l}\text { Coverage } \\
(\%)\end{array}$ & $\begin{array}{l}\text { Proteins } \\
\text { (\#) }\end{array}$ & $\begin{array}{l}\text { Unique } \\
\text { Peptides } \\
\text { (\#) }\end{array}$ & $\begin{array}{l}\text { Peptides } \\
\text { (\#) }\end{array}$ & $\begin{array}{l}\mathrm{MW} \\
{[\mathrm{kDa}]}\end{array}$ & $\begin{array}{l}\text { Spectral } \\
\text { count } \\
\text { Ratio } \\
\text { (SphCs } \\
\text { : skin } \\
\text { cells) }\end{array}$ \\
\hline P01033 & $\begin{array}{l}\text { Metalloproteinase } \\
\text { inhibitor } 1\end{array}$ & TIMP1 & 53.3 & 42.5 & 1 & 6 & 6 & 23.2 & 1.5 \\
\hline P62328 & $\begin{array}{l}\text { Thymosin beta- } \\
\text { 4;Hematopoietic } \\
\text { system regulatory } \\
\text { peptide }\end{array}$ & TMSB4X & 14.5 & 77.3 & 1 & 5 & 5 & 5.1 & 3.5 \\
\hline P51884 & Lumican & LUM & 67.3 & 34.9 & 1 & 7 & 9 & 38.4 & 1.6 \\
\hline $\begin{array}{l}\text { P06733;P13929; } \\
\text { P09104 }\end{array}$ & Alpha-enolase & EN01 & 17.6 & 12.4 & 3 & 4 & 4 & 47.2 & 1.6 \\
\hline 076061 & Stanniocalcin-2 & STC2 & 45.6 & 36.1 & 1 & 6 & 6 & 33.2 & 1.6 \\
\hline P23528;Q9Y281 & Cofilin-1 & CFL1 & 29.7 & 42.8 & 2 & 4 & 4 & 18.5 & 1.8 \\
\hline P63261 & $\begin{array}{l}\text { Actin, cytoplasmic } \\
\text { 2;Actin, cytoplasmic 2, } \\
\text { N-terminally processed }\end{array}$ & ACTG1 & 241.4 & 66.9 & 1 & 18 & 18 & 41.8 & 1.8 \\
\hline P63104 & $\begin{array}{l}\text { 14-3-3 protein } \\
\text { zeta/delta }\end{array}$ & YWHAZ & 130.8 & 17.6 & 5 & 2 & 3 & 27.7 & 2.1 \\
\hline 043707 & Alpha-actinin-4 & ACTN4 & 98.7 & 16.5 & 3 & 4 & 10 & 104.9 & 1.9 \\
\hline P31946 & $\begin{array}{l}14-3-3 \text { protein } \\
\text { beta/alpha; } 14-3-3 \\
\text { protein beta/alpha, N- } \\
\text { terminally processed }\end{array}$ & YWHAB & 3.6 & 9.8 & 1 & 1 & 2 & 28.1 & 2.3 \\
\hline P07737 & Profilin-1 & PFN1 & 6.6 & 27.1 & 1 & 2 & 3 & 15.1 & 2.2 \\
\hline Q16610 & $\begin{array}{l}\text { Extracellular matrix } \\
\text { protein } 1\end{array}$ & ECM1 & 51.1 & 33.9 & 1 & 10 & 10 & 60.7 & 2.1 \\
\hline $\begin{array}{l}\text { P68363;Q9BQE3; } \\
\text { Q71U36;P68366; } \\
\text { Q6PEY2;Q13748 }\end{array}$ & $\begin{array}{l}\text { Tubulin alpha-1B } \\
\text { chain; } \\
\text { alpha-1C chain; } \\
\text { alpha-1A chain; } \\
\text { alpha-4A chain; } \\
\text { alpha-3E chain; } \\
\text { alpha-3C/D chain }\end{array}$ & $\begin{array}{l}\text { TUBA1B; } \\
\text { TUBA1C; } \\
\text { TUBA1A; } \\
\text { TUBA4A; } \\
\text { TUBA3E; } \\
\text { TUBA3C }\end{array}$ & 12.9 & 14.6 & 7 & $\begin{array}{l}4 ; \\
3 ; \\
3 ; \\
2 ; \\
2 ; \\
2 ; 1\end{array}$ & $\begin{array}{l}4 ; \\
3 ; \\
3 ; \\
2 ; \\
2 ; \\
2 ; 1\end{array}$ & 50.2 & 2.1 \\
\hline $\begin{array}{l}\text { P21333;Q14315; } \\
\text { O75369 }\end{array}$ & Filamin-A & FLNA & 48.2 & 6.1 & 3 & $9 ; 2 ; 1$ & $9 ; 2 ; 1$ & 280.7 & 2.5 \\
\hline P26022 & $\begin{array}{l}\text { Pentraxin-related } \\
\text { protein PTX3 }\end{array}$ & РTX3 & 42.0 & 39.4 & 1 & 12 & 12 & 59.7 & 3.0 \\
\hline P03956 & $\begin{array}{l}\text { Interstitial } \\
\text { collagenase;22 kDa; } \\
27 \text { kDa }\end{array}$ & MMP1 & 77.6 & 28.8 & 1 & 11 & 11 & 54.0 & 21.0 \\
\hline
\end{tabular}

Table 2. Down-regulated proteins in the SphCs (spectral count SphCs / Parental skin cells $<0.65$ folds) 


\begin{tabular}{|c|c|c|c|c|c|c|c|c|c|}
\hline Accession & Description & $\begin{array}{l}\text { gene } \\
\text { name }\end{array}$ & Score & $\begin{array}{l}\text { Coverage } \\
(\%)\end{array}$ & $\begin{array}{l}\# \\
\text { Proteins }\end{array}$ & $\begin{array}{l}\# \\
\text { Unique } \\
\text { Peptides }\end{array}$ & $\begin{array}{l}\text { \# } \\
\text { Peptides }\end{array}$ & $\begin{array}{l}\mathrm{MW} \\
{[\mathrm{kDa}]}\end{array}$ & $\begin{array}{l}\text { Spectral } \\
\text { count } \\
\text { ratio } \\
\text { (MSC- } \\
\text { Sph/skin } \\
\text { culture) }\end{array}$ \\
\hline P16112 & $\begin{array}{l}\text { Aggrecan core } \\
\text { protein;Aggrecan core } \\
\text { protein } 2\end{array}$ & ACAN & 99,2 & 9 & 1 & 16 & 16 & 250,2 & 0,31 \\
\hline P02462;P29400 & $\begin{array}{l}\text { Collagen alpha-1(IV) } \\
\text { chain;Arresten }\end{array}$ & COL4A1 & 99,2 & 8,6 & 2 & $8 ; 1$ & $8 ; 1$ & 160,6 & 0,13 \\
\hline P05997 & $\begin{array}{l}\text { Collagen alpha-2(V) } \\
\text { chain }\end{array}$ & COL5A2 & 16,0 & 4,3 & 1 & 3 & 3 & 144,9 & 0,28 \\
\hline P15502 & Elastin & ELN & 73,0 & 24,8 & 1 & 9 & 9 & 68,5 & 0,28 \\
\hline P08572 & $\begin{array}{l}\text { Collagen alpha-2(IV) } \\
\text { chain;Canstatin }\end{array}$ & COL4A2 & 79,5 & 16,2 & 1 & 15 & 15 & 167,6 & 0,34 \\
\hline P02461 & $\begin{array}{l}\text { Collagen alpha-1(III) } \\
\text { chain }\end{array}$ & COL3A1 & 272,6 & 30,8 & 2 & $25 ; 7$ & $25 ; 7$ & 138,6 & 0,22 \\
\hline P02751 & $\begin{array}{l}\text { Fibronectin;Anastellin;Ugl- } \\
\text { Y1;Ugl-Y2;Ül-Y3 }\end{array}$ & FN1 & 323,3 & 45,1 & 1 & 71 & 71 & 262,6 & 0,44 \\
\hline P07996 & Thrombospondin-1 & THBS1 & 323,3 & 28,2 & 3 & 21 & 23 & 129,4 & 0,53 \\
\hline P02452 & Collagen alpha- $1(I)$ chain & COL1A1 & 323,3 & 63,7 & 3 & $56 ; 3 ; 1$ & $56 ; 3 ; 1$ & 138,9 & 0,35 \\
\hline Q9UBP4 & Dickkopf-related protein 3 & DKK3 & 49,2 & 38 & 1 & 8 & 8 & 38,4 & 0,50 \\
\hline 043852 & Calumenin & CALU & 37,3 & 23,8 & 1 & 7 & 7 & 37,1 & 0,32 \\
\hline P00736 & $\begin{array}{l}\text { Complement C1r } \\
\text { subcomponent; } \mathrm{C} 1 \mathrm{r} \\
\text { subcomponent heavy } \\
\text { chain;C1r subcomponent } \\
\text { light chain }\end{array}$ & C1R & 171,2 & 30,2 & 1 & 12 & 12 & 80,1 & 0,39 \\
\hline P08123 & Collagen alpha-2(I) chain & COL1A2 & 323,3 & 64,9 & 1 & 52 & 52 & 129,3 & 0,42 \\
\hline Q15582 & $\begin{array}{l}\text { Transforming growth } \\
\text { factor-beta-induced } \\
\text { protein ig-h3 }\end{array}$ & TGFBI & 323,3 & 49,8 & 1 & 23 & 23 & 74,7 & 0,64 \\
\hline P12110 & $\begin{array}{l}\text { Collagen alpha-2(VI) } \\
\text { chain }\end{array}$ & COL6A2 & 109,8 & 21,1 & 1 & 14 & 14 & 108,6 & 0,49 \\
\hline P20908 & $\begin{array}{l}\text { Collagen alpha- } 1(\mathrm{~V}) \\
\text { chain }\end{array}$ & COL5A1 & 16,2 & 4,7 & 1 & 5 & 5 & 183,6 & 0,52 \\
\hline P09486 & SPARC & SPARC & 177,9 & 52,5 & 1 & 12 & 12 & 34,6 & 0,50 \\
\hline Q12841 & $\begin{array}{l}\text { Follistatin-related protein } \\
1\end{array}$ & FSTL1 & 323,3 & 59,1 & 1 & 14 & 14 & 35,0 & 0,64 \\
\hline P35555 & Fibrillin-1 & FBN1 & 105,0 & 9,9 & 1 & 15 & 15 & 312,2 & 0,64 \\
\hline P09871 & $\begin{array}{l}\text { Complement C1s } \\
\text { subcomponent; C1s } \\
\text { subcomponent heavy } \\
\text { chain; C1s } \\
\text { subcomponent light } \\
\text { chain }\end{array}$ & C1S & 16,6 & 14,7 & 1 & 6 & 6 & 76,7 & 0,47 \\
\hline P21810 & Biglycan & BGN & 53,1 & 39,4 & 1 & 11 & 11 & 41,7 & 0,59 \\
\hline P98160 & $\begin{array}{l}\text { Basement membrane- } \\
\text { specific heparan sulfate } \\
\text { proteoglycan core } \\
\text { protein;Endorepellin;LG3 } \\
\text { peptide }\end{array}$ & HSPG2 & 14,8 & 1,5 & 1 & 4 & 4 & 468,8 & 0,64 \\
\hline
\end{tabular}


Table 3. Top hits of functional enrichment analysis in up-regulated proteins interaction network

\begin{tabular}{|c|c|c|c|}
\hline GO term & Description & counts in gene set & false discovery rate \\
\hline GO:0002576 & platelet degranulation & 5 of 129 & $4.23 e-05$ \\
\hline GO:0097435 & supramolecular fiber organization & 6 of 383 & 0.00010 \\
\hline GO:0048518 & positive regulation of biological process & 14 of 5459 & 0.00010 \\
\hline G0:0030036 & actin cytoskeleton organization & 6 of 418 & 0.00011 \\
\hline G0:0051130 & positive regulation of cellular component organization & 8 of 1128 & 0.00012 \\
\hline GO:0051220 & cytoplasmic sequestering of protein & 3 of 26 & 0.00016 \\
\hline GO:0051128 & regulation of cellular component organization & 10 of 2306 & 0.00016 \\
\hline GO:0050896 & response to stimulus & 15 of 7824 & 0.00016 \\
\hline G0:0048522 & positive regulation of cellular process & 13 of 4898 & 0.00016 \\
\hline G0:0032879 & regulation of localization & 10 of 2524 & 0.00020 \\
\hline GO:1902396 & protein localization to bicellular tight junction & 2 of 2 & 0.00029 \\
\hline G0:0045055 & regulated exocytosis & 6 of 691 & 0.00062 \\
\hline G0:0007165 & signal transduction & 12 of 4738 & 0.00067 \\
\hline GO:0030334 & regulation of cell migration & 6 of 753 & 0.00088 \\
\hline GO:0048519 & negative regulation of biological process & 12 of 4953 & 0.00095 \\
\hline G0:0007015 & actin filament organization & 4 of 200 & 0.00095 \\
\hline G0:0110053 & regulation of actin filament organization & 4 of 235 & 0.0013 \\
\hline GO:0051050 & positive regulation of transport & 6 of 892 & 0.0014 \\
\hline GO:0010638 & positive regulation of organelle organization & 5 of 552 & 0.0017 \\
\hline GO:2001044 & regulation of integrin-mediated signaling pathway & 2 of 13 & 0.0018 \\
\hline GO:0071345 & cellular response to cytokine stimulus & 6 of 953 & 0.0018 \\
\hline GO:0051239 & regulation of multicellular organismal process & 9 of 2788 & 0.0018 \\
\hline G0:0048523 & negative regulation of cellular process & 11 of 4454 & 0.0018 \\
\hline GO:0042981 & regulation of apoptotic process & 7 of 1501 & 0.0018 \\
\hline GO:0050794 & regulation of cellular process & 15 of 10484 & 0.0022 \\
\hline GO:0010155 & regulation of proton transport & 2 of 16 & 0.0022 \\
\hline GO:0007166 & cell surface receptor signaling pathway & 8 of 2198 & 0.0022 \\
\hline
\end{tabular}

Table 4. Top hits of Functional enrichment analysis in down-regulated proteins interaction network 


\begin{tabular}{|c|c|c|c|}
\hline GO term & Description & counts in gene set & false discovery rate \\
\hline GO:0030198 & extracellular matrix organization & 17 of 296 & $4.68 \mathrm{e}-24$ \\
\hline G0:0072359 & circulatory system development & 13 of 807 & $1.32 \mathrm{e}-10$ \\
\hline GO:0001568 & blood vessel development & 10 of 464 & $7.99 \mathrm{e}-09$ \\
\hline G0:0030199 & collagen fibril organization & 5 of 39 & $1.69 \mathrm{e}-07$ \\
\hline GO:0009653 & anatomical structure morphogenesis & 14 of 1992 & $2.47 e-07$ \\
\hline GO:0071230 & cellular response to amino acid stimulus & 5 of 60 & $9.86 \mathrm{e}-07$ \\
\hline GO:0001501 & skeletal system development & 8 of 457 & $2.32 \mathrm{e}-06$ \\
\hline GO:0071363 & cellular response to growth factor stimulus & 8 of 477 & $2.92 \mathrm{e}-06$ \\
\hline GO:0048514 & blood vessel morphogenesis & 7 of 381 & $1.09 \mathrm{e}-05$ \\
\hline GO:0038063 & collagen-activated tyrosine kinase receptor signaling pathways & 3 of 9 & $1.83 e-05$ \\
\hline GO:0048731 & system development & 16 of 4144 & $2.11 \mathrm{e}-05$ \\
\hline GO:0071560 & cellular response to transforming growth factor beta stimulus & 5 of 140 & $2.97 e-05$ \\
\hline GO:0018149 & peptide cross-linking & 4 of 59 & $3.48 \mathrm{e}-05$ \\
\hline GO:0070208 & protein heterotrimerization & 3 of 14 & $3.74 \mathrm{e}-05$ \\
\hline GO:0009719 & response to endogenous stimulus & 10 of 1353 & $3.74 \mathrm{e}-05$ \\
\hline GO:0001525 & angiogenesis & 6 of 297 & $3.74 \mathrm{e}-05$ \\
\hline GO:0071310 & cellular response to organic substance & 12 of 2219 & $4.08 \mathrm{e}-05$ \\
\hline GO:0001101 & response to acid chemical & 6 of 323 & $5.02 \mathrm{e}-05$ \\
\hline GO:0051241 & negative regulation of multicellular organismal process & 9 of 1098 & $5.49 \mathrm{e}-05$ \\
\hline GO:0035295 & tube development & 8 of 793 & $5.49 e-05$ \\
\hline G0:0010033 & response to organic substance & 13 of 2815 & $5.56 \mathrm{e}-05$ \\
\hline GO:0007155 & cell adhesion & 8 of 843 & $7.29 e-05$ \\
\hline GO:0048513 & animal organ development & 13 of 2926 & $7.45 \mathrm{e}-05$ \\
\hline GO:0051093 & negative regulation of developmental process & 8 of 910 & 0.00011 \\
\hline GO:0016525 & negative regulation of angiogenesis & 4 of 99 & 0.00013 \\
\hline GO:0042060 & wound healing & 6 of 461 & 0.00023 \\
\hline G0:0050896 & response to stimulus & 19 of 7824 & 0.00024 \\
\hline
\end{tabular}

\section{Figures}




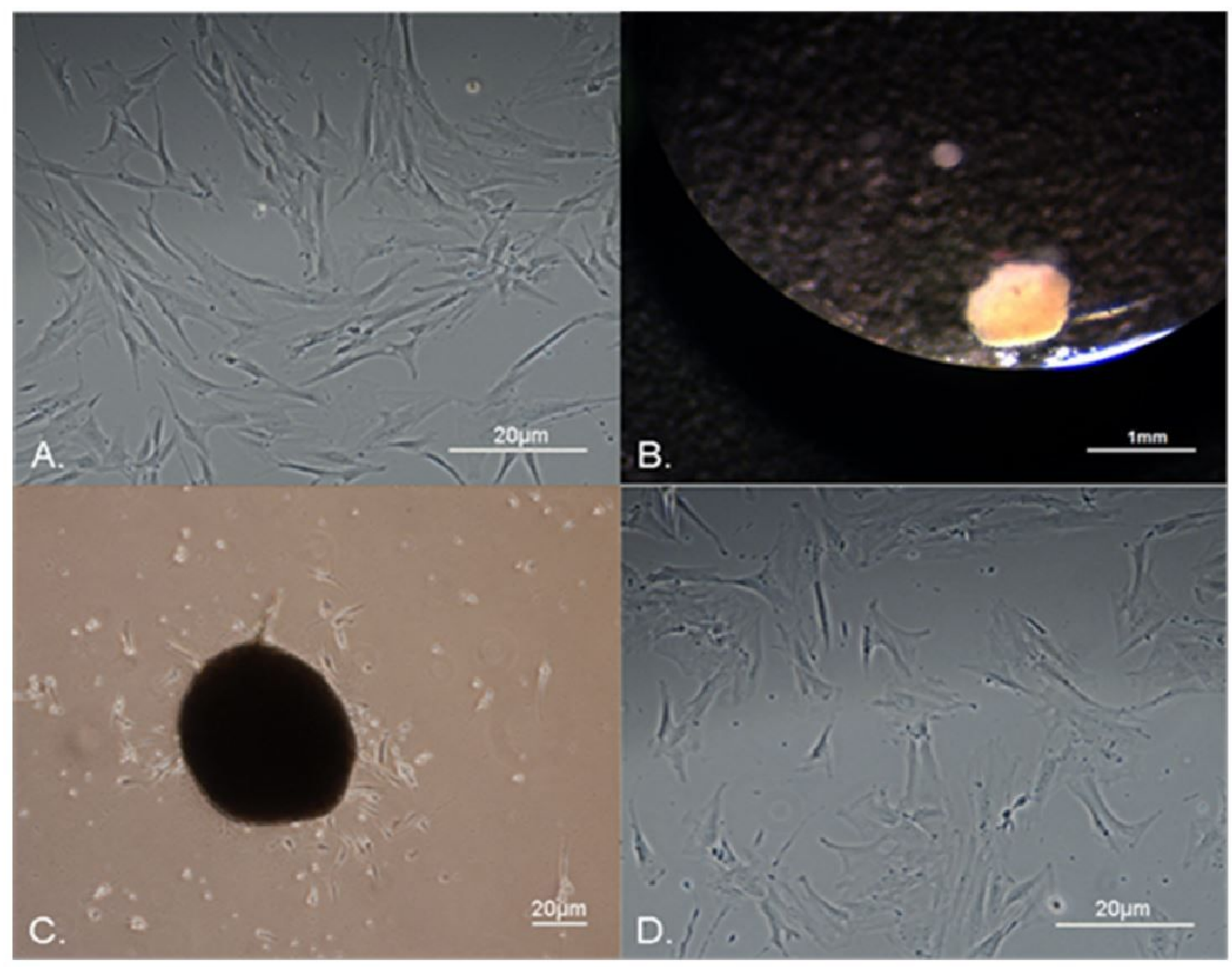

\section{Figure 1}

Hanging-drop culture of adult human skin fibroblast-like cells. A.) Micrograph showing the representative appearance of adult human primary skin cells on adherent plastic, evidencing fibroblast-like forms; scale bar $=20 \mu \mathrm{m}$. B.) A representative spheroid of skin-derived cells formed after a hanging drop $72 \mathrm{~h}$ culture; scale bar= $1 \mathrm{~mm}$. C.) Spheroids were seeded on adherent plastic with cells spontaneously migrating from it; scale bar $=20 \mu \mathrm{m}$. D.) Spheroid-derived cells (SphCs) in adherent plastic culture exhibiting similar morphology to their original primary skin cell counterparts; scale bar $=20 \mu \mathrm{m}$. 
A.
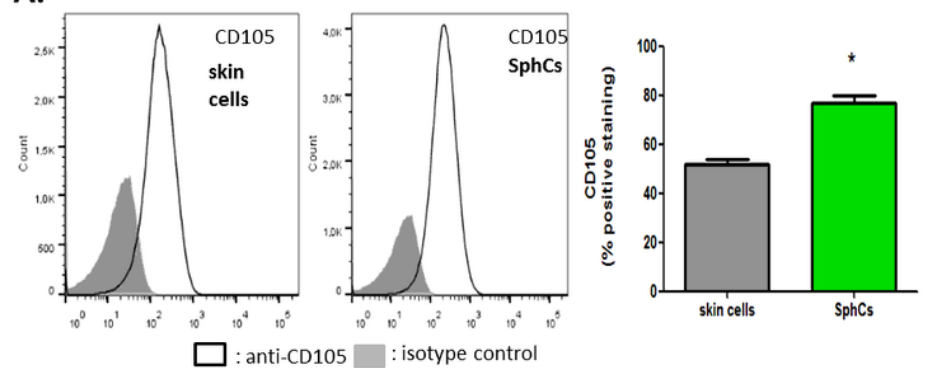

B.
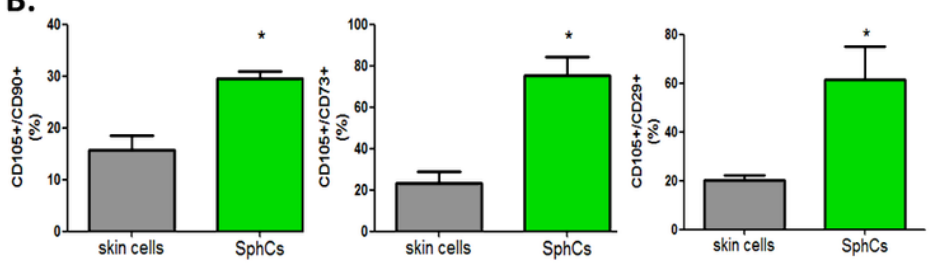

C.
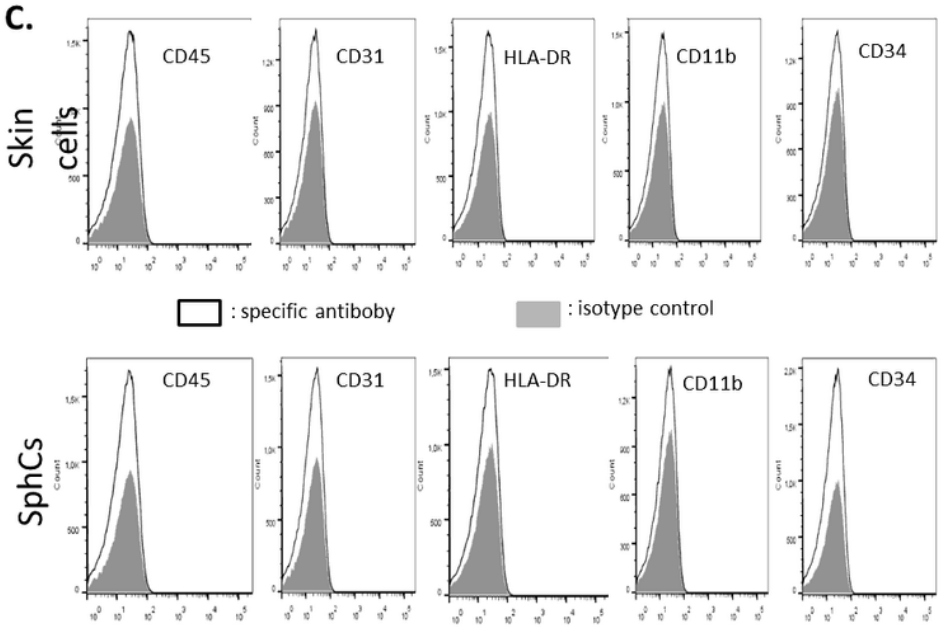

specific antiboby

: isotype control
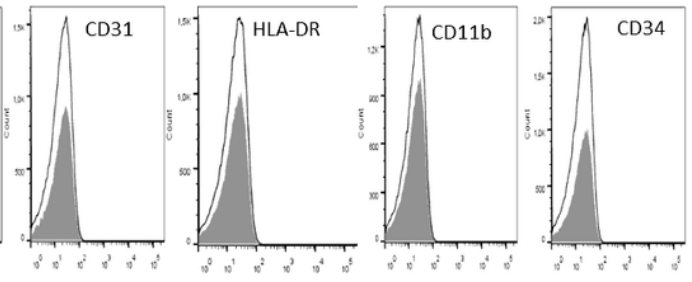

\section{Figure 2}

Phenotypic characterization of spheroid-derived cells (SphCs). The surface expression pattern of cluster of differentiation (CD) of SphCs was evaluated from three different patients, and their skin fibroblast-like cell (skin cells) counterparts were employed for comparison. A.) Representative distribution graphs of surface CD105 expression obtained by flow cytometry. The histogram shows the percentage of cells expressing CD105. B.) Quantification, using flow cytometry, of cells expressing double-positive CD markers as indicated in the figure. C.) Distribution of skin cells from one donor (upper panel) and SphCs (lower panel) expressing surface human leukocyte antigen-DR (HLA-DR), panleukocyte (CD45), hematopoietic progenitor (CD34), monocyte/macrophage (CD11b) and endothelial (CD31) markers. Similar distribution graphs were obtained with the other two samples. The distribution of CDs in A and $\mathrm{C}$ is depicted in white, and isotype antibodies are depicted in gray. Data are presented as the mean $\pm S E M ; n=3$ independent experiments for each skin cell donor and the corresponding SphCs. ${ }^{*} p<0.05$ vs skin cells. 

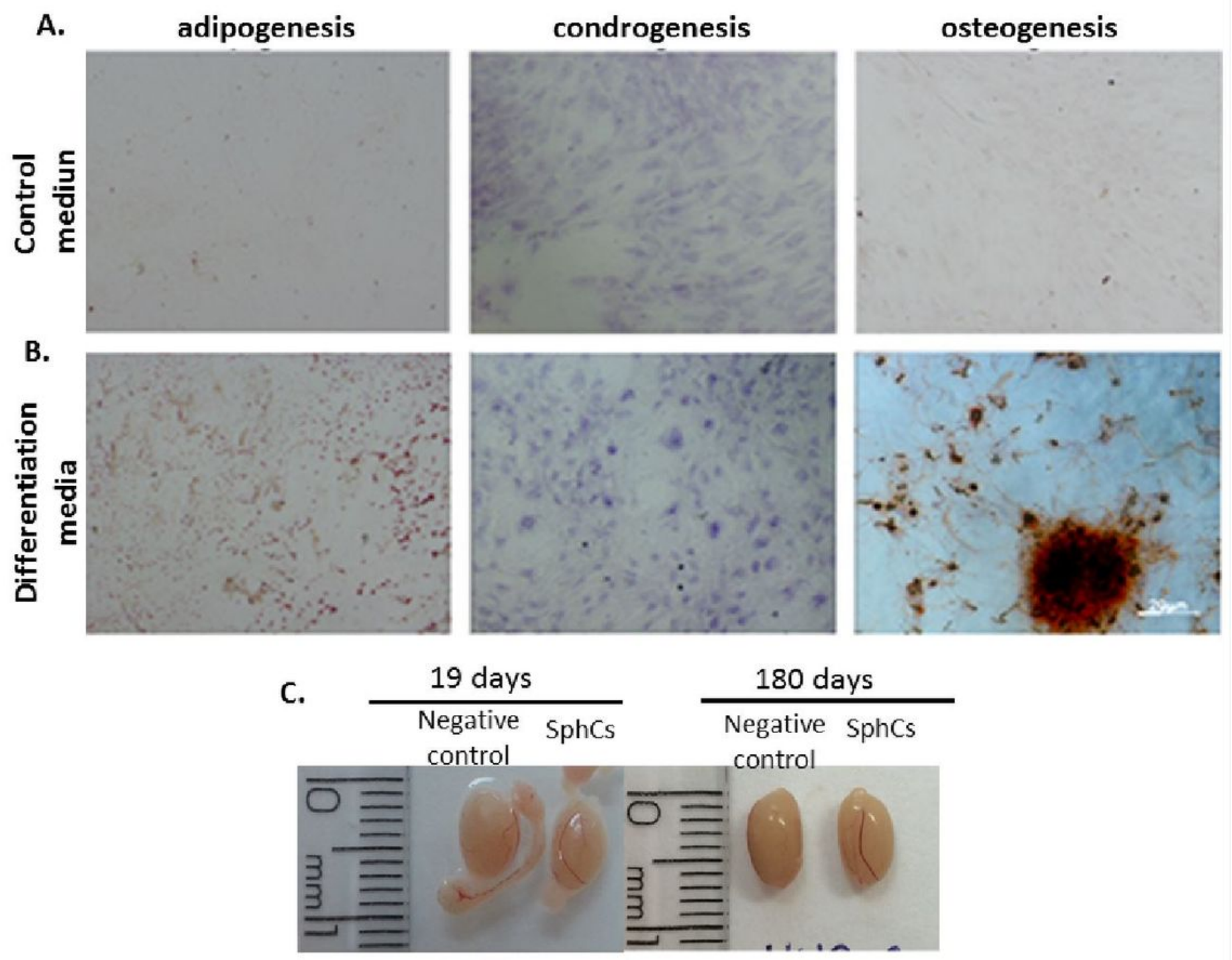

\section{Figure 3}

Spheroid-derived cells (SphCs) differentiate into the three germ cell lineages. A.) SphCs grown in adherent plastic with culture medium. B.) SphCs were grown in the presence of tissue-specific differentiation media for 21 days and then fixed and stained with adipocyte (solution $0.5 \%$ Oil Red $\mathrm{O}$ in isopropanol, $15 \mathrm{~min}$ ), chondrocyte (toluidine blue $0.1 \%, 30 \mathrm{~min}$ ) or osteocyte ( $2 \%$ Alizarin red, $15 \mathrm{~min}$ )-specific dyes. Representative images (magnification 100X). C.) BALB/c nude mice were subjected to either an intratesticular (i.t.) injection of PBS as a negative control (left image of each panel) or SphC cell suspension (1×105 in PBS) in the contralateral testis (right figure of each panel). The images show the testes at 19 and 180 days after i.t. injection of SphCs. Testes presented a normal size and morphology until 180 days of observation. 


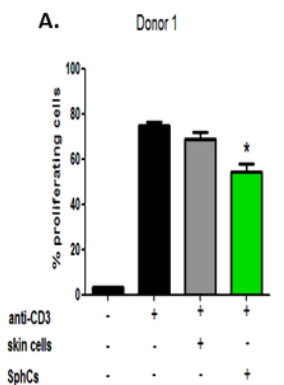

B.

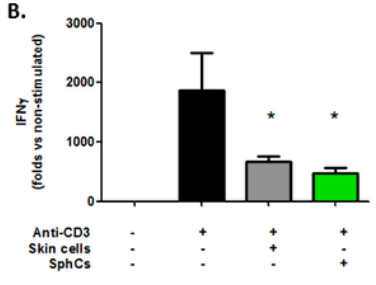

D.
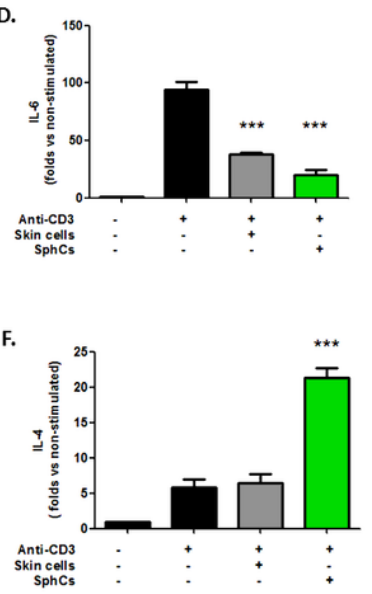

Donor 2

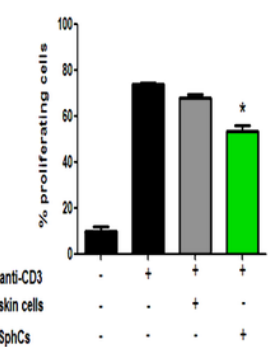

c.

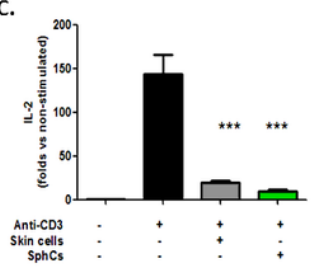

E.

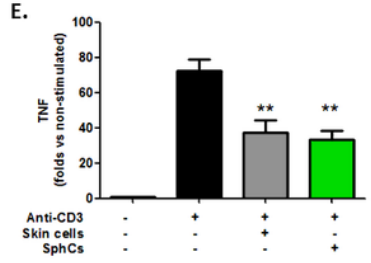

G.

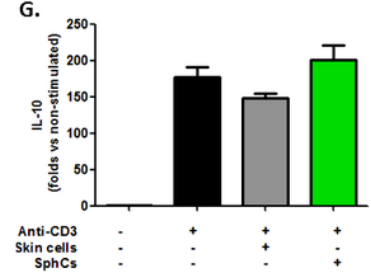

\section{Figure 4}

Spheroid-derived cells (SphCs) modulate immune cell responses in vitro. A.) Anti-CD3-stimulated splenocytes (as responder cells; 5x105) were coincubated with SphCs (1x104) or, alternatively, with primary skin cells (1x104). Proliferation was evaluated by CFSE dilution in T$\mathrm{CD} 4+$ lymphocytes by flow cytometry. Assays were performed employing two different donors; $n=4$ independent experiments. B-G.) Cytokine secretion by activated splenocytes was biased in the presence of SphCs. Splenocytes were activated by an anti-CD3-coated surface. Secreted cytokines were quantified by CBA multiplex assay. B.) IFN-y. C.) IL-2. D.) IL-6. E.) TNF-a. F.) IL-4. G.) IL-10. ${ }^{\star} p<0.05,{ }^{\star \star} p<0.01,{ }^{\star \star \star} p$ $<0.001$ vs. anti-CD3 stimulated splenocytes. Data are presented as the mean $\pm S E M ; n=3$ independent experiments. 


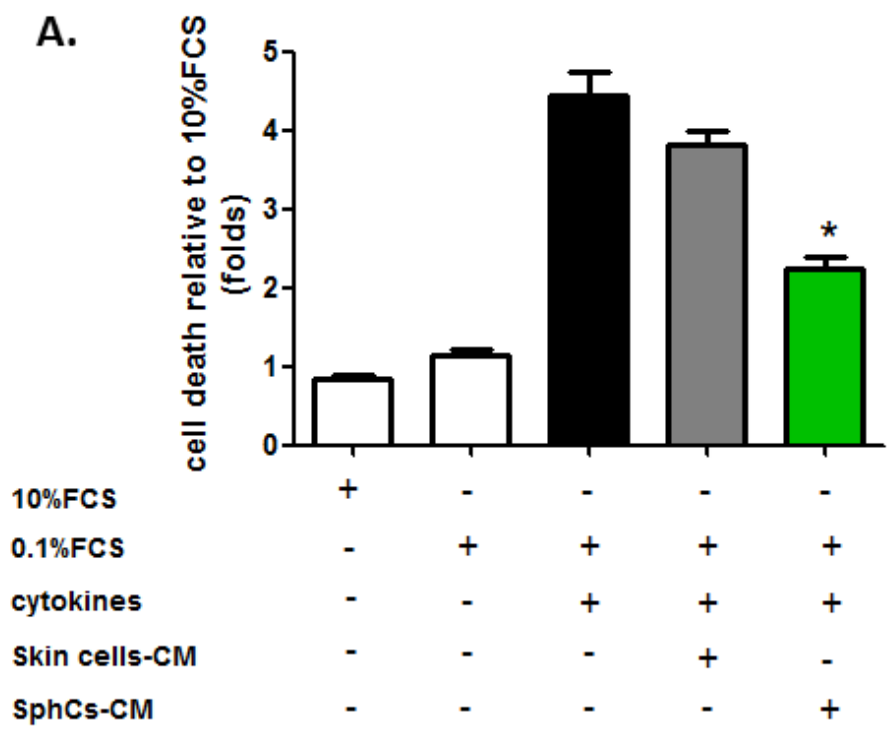

B.

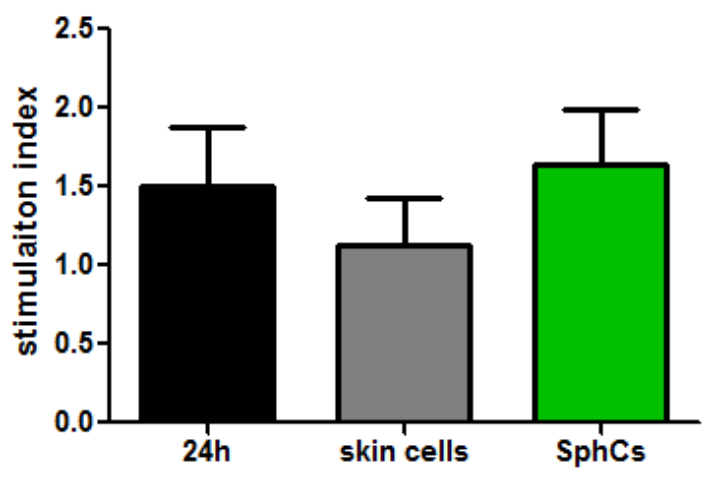

C.

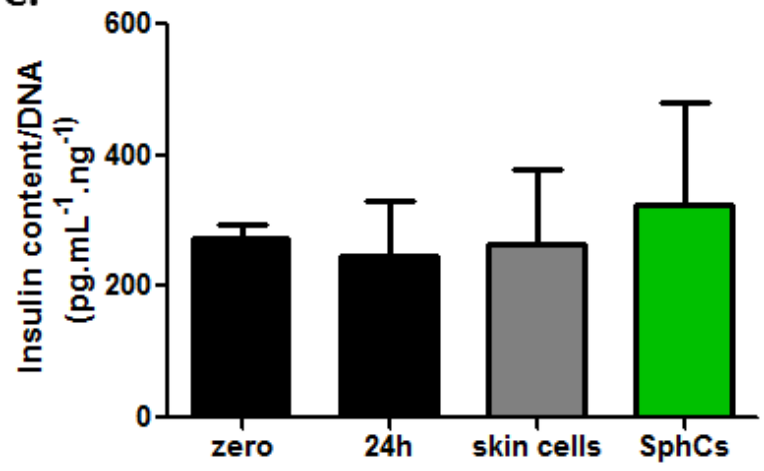

\section{Figure 5}

Spheroid-derived cell (SphCs)-conditioned media attenuate cytokine-induced islet cell death without altering insulin secretion. A.) Cell death in isolated murine islets was evaluated after $24 \mathrm{~h}$ of incubation $(0.1 \% \mathrm{FCS})$ and challenged with a cocktail of proinflammatory cytokines supplemented or not with $20 \% \mathrm{~V} / \mathrm{V}$ conditioned media from parental skin cells (skin cell-CM) or, alternatively, (SphCs-CM). Values were calculated relative to the negative control condition ( $10 \% \mathrm{FCS}$ ). ${ }^{*} \mathrm{p}<0.05$ vs. cytokines and skin cell-derived CM. Data are presented as the mean \pm SEM; $n=4$ independent experiments (each experiment included at least 8 islets analyzed per condition). B.) Glucose-stimulated insulin secretion (stimulation index) of islets under $24 \mathrm{~h}$ of $\mathrm{CM}$ from skin cells or SphCs. The stimulation index was calculated as follows: (secreted insulin concentration in $16.7 \mathrm{mM}$ glucose buffer)/(secreted insulin concentration in $2.8 \mathrm{~mm}$ glucose buffer). Data are presented as the mean \pm SEM; $n=3$ independent experiments. C.) Total insulin content in murine islets under $24 \mathrm{~h}$ of $\mathrm{CM}(20 \% \mathrm{~V} / \mathrm{V})$ from skin cells or SphCs. Insulin was measured by ELISA and normalized to DNA content. Data are presented as the mean \pm SEM; $n=3$ independent experiments. 


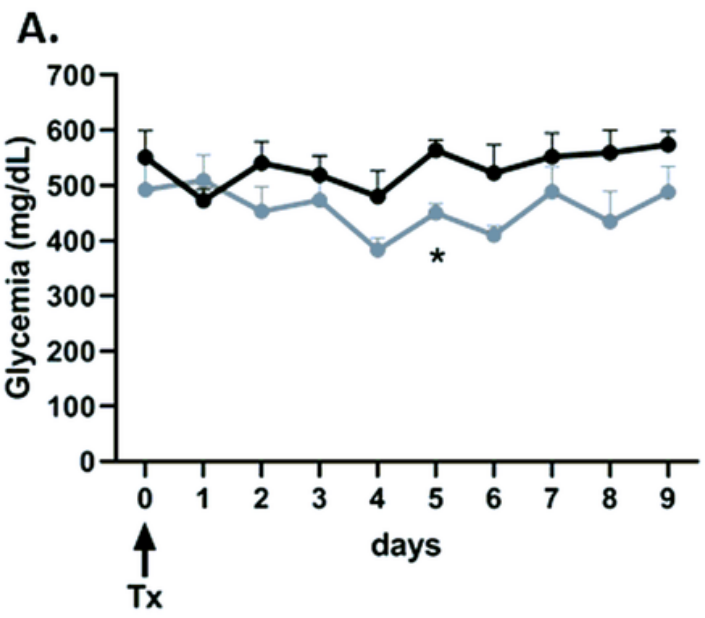

B.
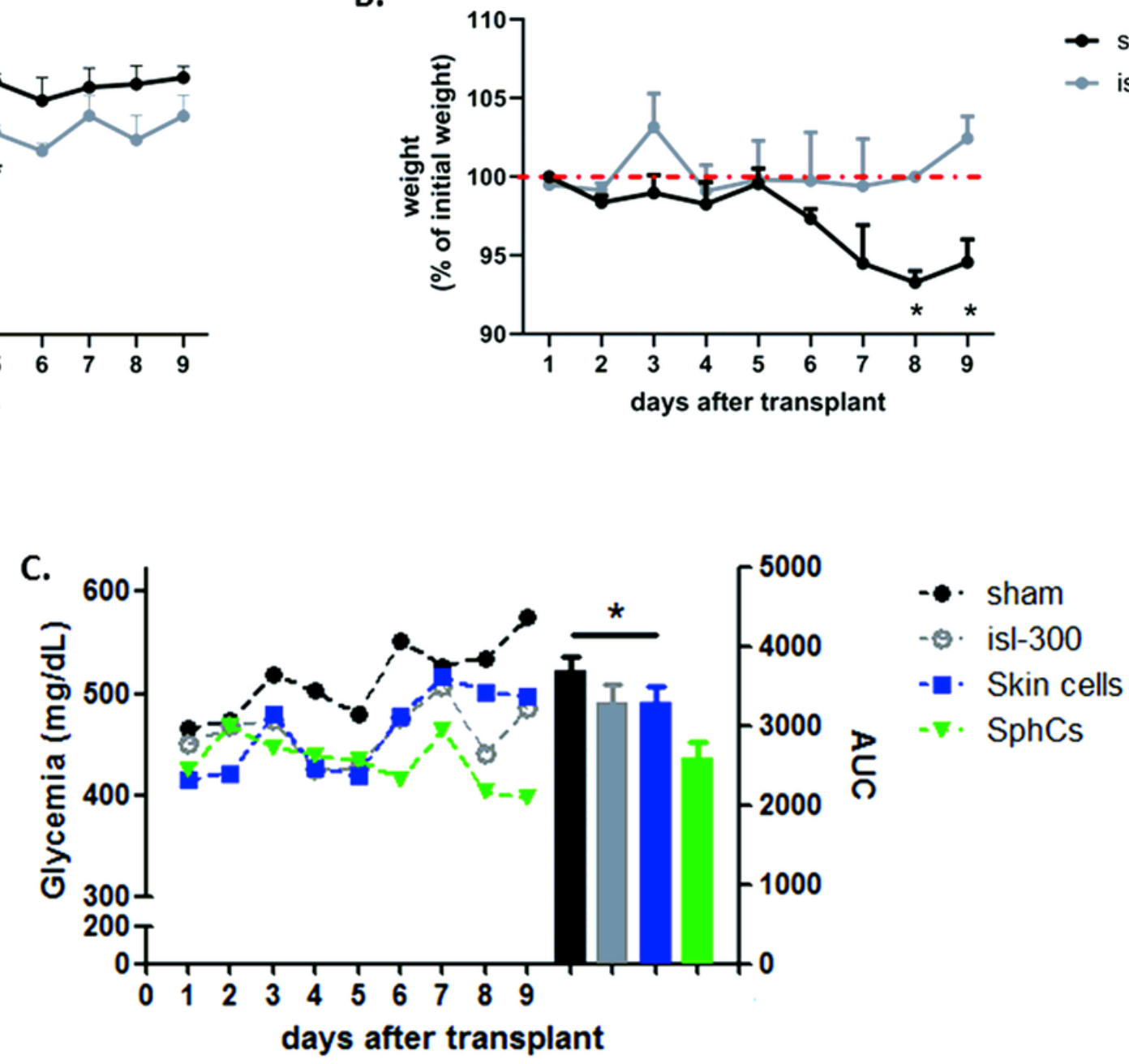

Figure 6

Cotransplantation of marginal mass allogeneic islets with SphCs improves glycemic control in diabetic mice A.) Establishment of the marginal mass allogenic islets. Both 300 IEQ-transplanted and sham-transplanted diabetic mice showed no difference in blood glucose. Data are presented as the mean \pm SEM ( $n=3$ mice per experimental group); ${ }^{p}<<0.05$ vs. sham and isl-300. B.) $300 I E Q$ recipient diabetic mice did not lose body weight. In contrast, sham-operated mice lost significant body weight as of 6 days after the surgical procedure. Data are presented as the mean \pm SEM ( $n=3$ mice per experimental group) ${ }^{*} p<0.05$ vs. isl-300. C.) Cotransplantation of marginal mass allogenic islets with SphCs $(1 \times 104)$ improved glycemia in diabetic mice. The results are shown as plasma glucose concentration in the animals at different time points (left $Y$ axis) and by integrating the area under the curve (AUC) as depicted in the right " $Y$ " axis. Data are presented as the mean \pm SEM ( $n=9$ mice per experimental group) * $p<0.05$ vs. SphCs. 

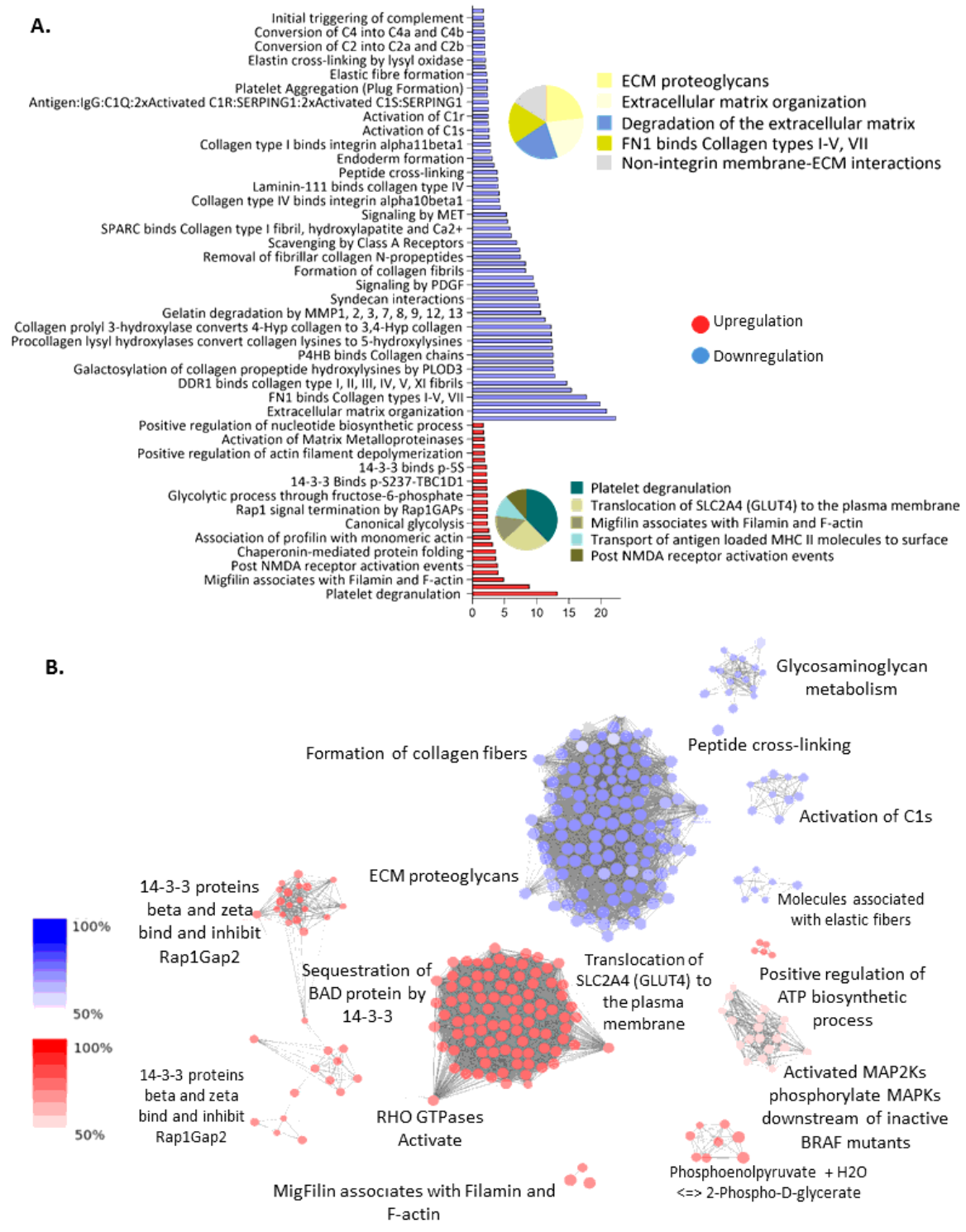

Figure 7

Protein secretome analysis of SphCs compared to that obtained in primary cultures of skin cells A) Biological processes and enriched molecular pathways associated with differentially regulated proteins (q-value $<0.05$, Bonferroni, ClueGO app) in the secretome of SphCs compared with skin fibroblast-like cells. The colors red and blue indicate upregulated and downregulated ontologies, respectively. B) Cluster networks of protein-protein interactions corresponding to the main processes described in A were analyzed by the STRING database. A minimum required interaction score of 0.7 was used to build a high confidence interaction network. The line connecting the proteins, depicted as spheres, shows experimental evidence of interaction between them. Each network presents a PPI enrichment value $<1$ exp-6. 